\title{
Marine-Derived Indole Alkaloids and Their Biological and Pharmacological Activities ${ }^{\dagger}$
}

\author{
Joko Tri Wibowo ${ }^{1}\left(\mathbb{D}\right.$, Peni Ahmadi ${ }^{1}$, Siti Irma Rahmawati ${ }^{1}$, Asep Bayu ${ }^{1}$, Masteria Yunovilsa Putra ${ }^{1} * *(\mathbb{C}$ \\ and Anake Kijjoa ${ }^{2, *(D)}$ \\ 1 Research Center for Biotechnology, Life Sciences Research Organization, National Research and Innovation \\ Agency (BRIN), Jl. Raya Bogor Km. 46, Cibinong 16911, Indonesia; joko.tri.wibowo@brin.go.id (J.T.W.); \\ peni.ahmadi@brin.go.id (P.A.); siti.irma.rahmawati@brin.go.id (S.I.R.); asep044@brin.go.id (A.B.) \\ 2 ICBAS-Instituto de Ciências Biomédicas Abel Salazar and CIIMAR, Universidade do Porto, \\ Rua de Jorge Viterbo Ferreira, 228, 4050-313 Porto, Portugal \\ * Correspondence: masteria.yunovilsa.putra@brin.go.id (M.Y.P.); ankijjoa@icbas.up.pt (A.K.); \\ Tel.: +62-2-18754587 (M.Y.P.); +351-22-042-8331 (A.K.); Fax: +351-22-206-2232 (A.K.) \\ + Dedicated to Prof. Guido Cimino for the occasion of his 80th birthday.
}

Citation: Wibowo, J.T.; Ahmadi, P.; Rahmawati, S.I.; Bayu, A.; Putra, M.Y.; Kijjoa, A. Marine-Derived Indole Alkaloids and Their Biological and Pharmacological Activities. Mar. Drugs 2022, 20,3. https:/ / doi.org/ $10.3390 / \mathrm{md} 20010003$

Academic Editors: Angelo Fontana and Margherita Gavagnin

Received: 5 December 2021

Accepted: 16 December 2021

Published: 21 December 2021

Publisher's Note: MDPI stays neutral with regard to jurisdictional claims in published maps and institutional affiliations.

Copyright: (C) 2021 by the authors. Licensee MDPI, Basel, Switzerland. This article is an open access article distributed under the terms and conditions of the Creative Commons Attribution (CC BY) license (https:// creativecommons.org/licenses/by/ $4.0 /)$.

\begin{abstract}
Novel secondary metabolites from marine macroorganisms and marine-derived microorganisms have been intensively investigated in the last few decades. Several classes of compounds, especially indole alkaloids, have been a target for evaluating biological and pharmacological activities. As one of the most promising classes of compounds, indole alkaloids possess not only intriguing structural features but also a wide range of biological/pharmacological activities including antimicrobial, anti-inflammatory, anticancer, antidiabetic, and antiparasitic activities. This review reports the indole alkaloids isolated during the period of 2016-2021 and their relevant biological/pharmacological activities. The marine-derived indole alkaloids reported from 2016 to 2021 were collected from various scientific databases. A total of 186 indole alkaloids from various marine organisms including fungi, bacteria, sponges, bryozoans, mangroves, and algae, are described. Despite the described bioactivities, further evaluation including their mechanisms of action and biological targets is needed to determine which of these indole alkaloids are worth studying to obtain lead compounds for the development of new drugs.
\end{abstract}

Keywords: indole alkaloids; marine natural products; bioactive compounds; marine-derived fungi; marine sponges

\section{Introduction}

Marine natural products (MNPs) have drawn much attention from both natural product chemists and pharmacologists due to their potential bioactivities. These chemical compounds have made a major contribution for the treatment of a myriad of diseases including cancer and infectious diseases as well as other therapeutic areas such as multidrug resistances (MDRs), cardiovascular diseases, and multiple sclerosis [1,2]. Compared to conventional synthetic molecules, MNPs present several advantages due to their unique structural features and complex scaffolds that are beneficial for drug discovery. MNPs usually possess high molecular weight and a large number of carbon and oxygen atoms. Moreover, marine-derived bioactive compounds have fewer but unique nitrogen and halogen atoms.

Alkaloids are a class of compound that contain organic nitrogenous bases [3]. Marinederived alkaloids, especially indole alkaloids, exhibit a myriad of biological activities such as antibacterial, antifungal, anti-inflammatory, antileishmanial, antiplasmodial, antiHIV, cytotoxic, glucose uptake stimulatory, larvicidal, trypanocidal, vasodilatory, and anti-cholinesterase activities [4]. Moreover, the alkaloids obtained from marine organisms frequently possess novel scaffolds that are not found in terrestrially related organisms [3]. 
Indole alkaloids are a class of alkaloids containing an indole moiety. Generally, indole alkaloids can be classified into four groups, viz. simple indole alkaloids, prenylated indoles, bis-/tris-indoles, and annelated indoles [5] (Figure 1). Simple indole alkaloids are mostly derived from the amino acid tryptophan (Trp) or its direct precursor, indole, in microorganisms or plants. On the other hand, prenylated indoles represent diverse groups of indole alkaloids that are commonly derived from Trp and isoprene unit(s) whereas bisand tris-indoles are biosynthetically derived from two or three indole building blocks. For annelated indoles, a single indole core is fused with non-prenyl-derived (hetero)cyclic ring systems.

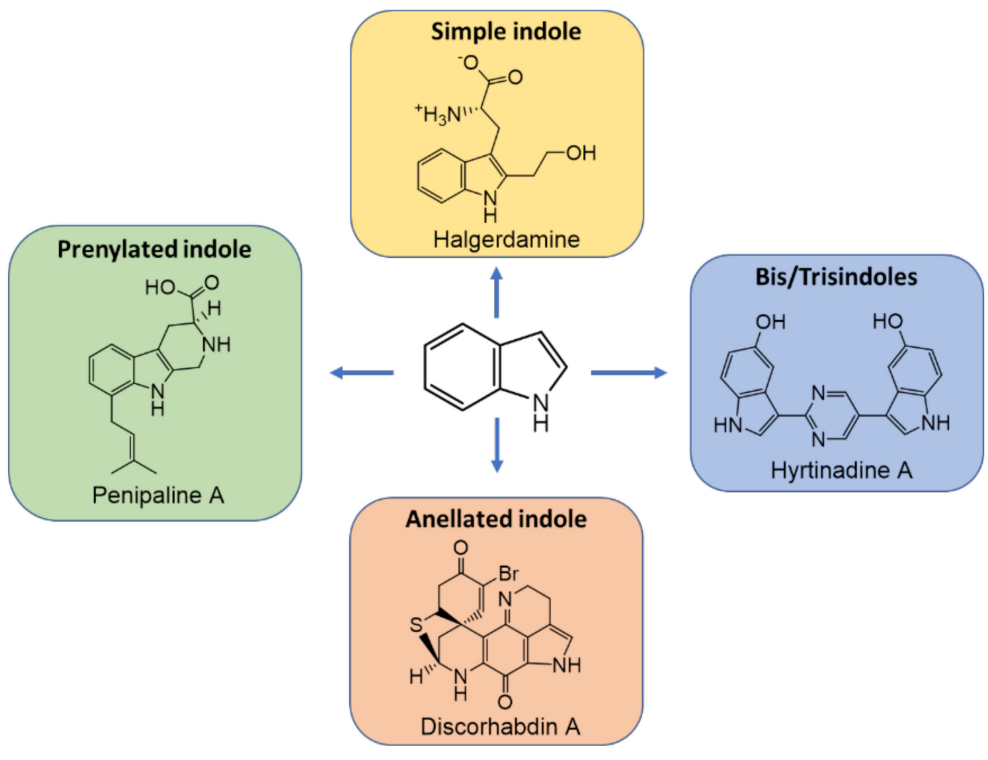

Figure 1. Classification of indole alkaloids based on chemical structures.

Besides several specific reviews on marine-derived indole alkaloids focusing on their biological and pharmacological activities $[3,4,6]$, a comprehensive review by Netz and Opatz [5] has previously been published. In the present review, we have updated the indole alkaloids, isolated from various marine macro- and microorganisms including fungi, bacteria, sponges, bryozoans, mangrove plants, and algae during the period of January 2016 to October 2021. However, we only report the previously undescribed compounds isolated during this period, while the compounds reported before this period and are mentioned in the references used in this review are not included. The relevant biological and pharmacological activities of some potential alkaloids are also highlighted. The search engines used to find the compounds in this review were PubMed, MEDLINE, Web of Science, and Scopus.

Since our main research topics involved a discovery of new secondary metabolites from marine-derived fungi, marine invertebrates, and algae, which led to the isolation of a number of undescribed and structurally diverse indoles such as prenylated and annelated indoles with antibacterial and antibiofilm activities, this topic can provide us and other researchers who work with marine natural products to gain more insight into this class of compounds in both structural and biological activity aspects.

\section{Sources of Marine-Derived Indole Alkaloids Isolated from January 2016 to October 2021}

The marine ecosystem has raised the awareness of natural product chemists due to the prospects of biologically active MNPs as a great potential for pharmaceuticals and cosmeceuticals. One of the most interesting classes of MNPs is indole alkaloids. Based on the literature search, 186 previously undescribed marine indole alkaloids that were isolated from various phyla of marine organisms including fungi, bacteria, sponges, bryozoans, 
mangrove trees, and algae have been reported between January 2016 and October 2021 (Figure 2). Intriguingly, many of these indole alkaloids possess unique structural features as well as interesting biological and pharmacological activities.

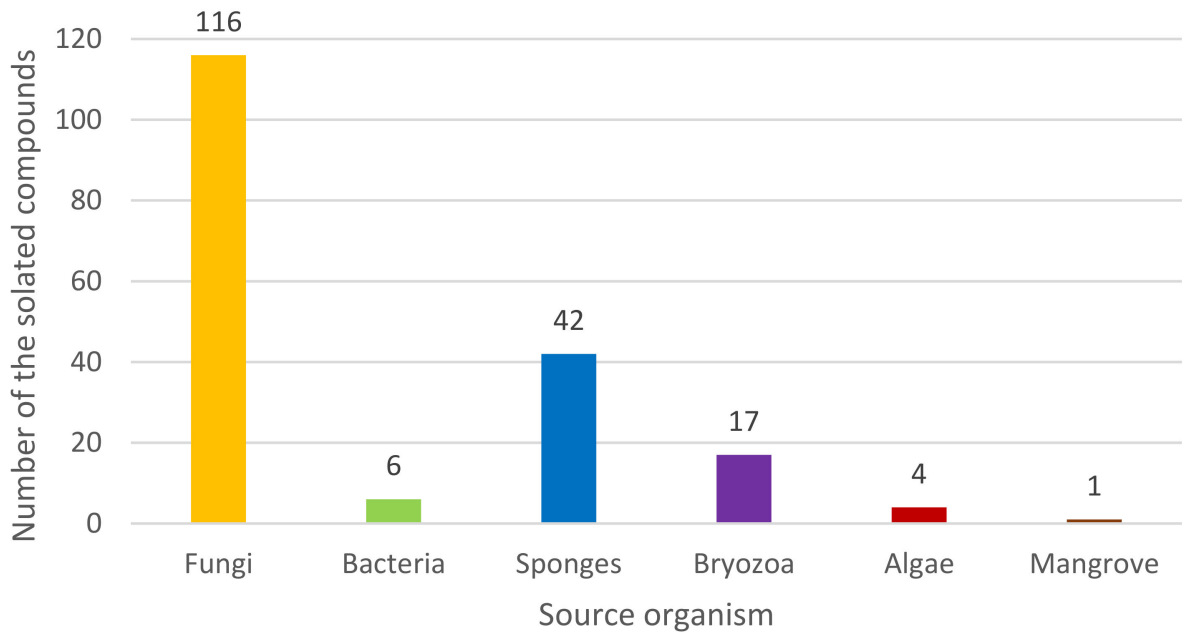

Figure 2. Distribution of the marine-derived indole alkaloids isolated from source organisms from January 2016 to October 2021.

\subsection{Marine Microorganisms}

\subsubsection{Marine-Derived Fungi}

Marine-derived fungi have been shown to be a prolific source of indole alkaloids, especially the prenylated indole alkaloids. For practical aspects and a better insight for the readers, the previously unreported indole alkaloids isolated from marine-derived fungi (and other marine organisms) are divided into four groups as above-mentioned.

\section{Simple Indole Alkaloids}

Although marine sponges and soft coral-associated fungi are rich sources of indole alkaloids, other marine invertebrates such as sea star and sea cucumber are also found to host indole alkaloid-producing fungi. In order to facilitate the perception, the compounds of this group are not ordered according to the type of host organisms, but according to the complexity of the substituents of the indole core, starting from acyclic substituents to cyclic ones. For cyclic substituents, the order of the compounds is from monocyclic and progressing to bi-, tri-, and polycyclic, respectively.

Supplementation of L-Trp into Glucose-Yeast-Peptone (GYP) culture medium of the fungus Fusarium sp. L1, which was isolated from the inner tissue of a sea star Acanthaster planci collected from the Xisha Islands in China, resulted in the production of two previously unreported simple indole alkaloids, fusariumindole C (1) and ( \pm )-isoalternatine A (2) (Figure 3) [7].

A marine-derived fungus Dichotomomyces cejpii F31-1, obtained from the inner tissue of a soft coral Lobophytum crassum that was collected from the Hainan Sanya National Coral Reef Reserve, China, yielded an indole-containing amide, dichotomocej D (3) (Figure 3) [8]. Pseudellone D (4) (Figure 3), a metylsulfanyldiketopiperazine-containing indole, was also obtained from the culture of the fungus Pseudallescheria ellipsoidea F42-3, which was isolated from the inner tissue of the soft coral L. crassum collected from the Hainan Sanya National Coral Reef Reserve, China [9].

A marine fungus Engyodontium album (IVB1b), isolated from a marine sponge Ircinia variabilis that was collected at İlyosta-Ayvalık in Balıkesir, Turkey, produced 1-(4-hydroxybenzoyl) indole-3-carbaldehyde (5) (Figure 3) [10].

Mycelia of a fungus Scedosporium apiospermum F41-1, also obtained from the inner tissue of the soft coral L. crassum that was collected from the Hainan Sanya National Coral Reef Reserve, China, yielded scequinadoline J (6) (Figure 3). The absolute configuration of the 
stereogenic carbon (C-14) in $\mathbf{6}$ was established by a comparison of the calculated and experimental electronic circular dichroism (ECD) spectra [11]. Interestingly, the same fungus produced different metabolites including an undescribed pyrazinoquinazolinone-containing indole, scequinadoline G (7), when cultured in the GYP medium supplementation of L-Trp, L-Phe, L-Thr, and D,L-Met from when it was cultured solely in GPY medium [12].

Sartoryglabramide B (8) (Figure 3), an indole-containing tetrapeptide, was isolated from the culture of a marine sponge-associated fungus Neosartorya glabra KUFA 0702A, which was isolated from the marine sponge Mycale sp., collected at Samaesarn Island in the Gulf of Thailand. The absolute configurations of the amino acid constituents were determined by X-ray analysis and confirmed by chiral high performance liquid chromatography (HPLC) analysis of its hydrolysate and compared with D- and L-amino acid standards [13].<smiles>O=C(O[C@H](Cc1ccccc1)C(=O)O)c1c[nH]c2ccccc12</smiles><smiles>C/C=C/C=C(\C)C(=O)NC(COC(=O)Cc1c[nH]c2ccccc12)CC(C)C</smiles><smiles>C[C@H]1NC(=O)[C@](C)(S)NC1=O</smiles>

4<smiles>O=Cc1cn(C(=O)c2ccc(O)cc2)c2ccccc12</smiles><smiles>C/C=C1\NC(=O)[C@H](Cc2c[nH]c3ccccc23)n2c1nc1ccccc1c2=O</smiles><smiles>CC(C)=C1NC[C@H](CC2(O)C(=O)Nc3ccccc32)n2c1nc1ccccc1c2=O</smiles><smiles>O=C(Nc1ccccc1C(=O)N1CCC[C@H]1C(=O)O)[C@H](Cc1c[nH]c2ccccc12)NC(=O)[C@H](Cc1ccccc1)NC(=O)[C@H]1CCCN1</smiles>

7

Figure 3. Structures of 1-8.

\section{Prenylated Indoles}

Similar to the simple indole alkaloids, the prenylated indoles are not ordered according to the producing fungi, but according to their structural complexity, starting from a simple indole core with acyclic prenyl substituents to cyclic prenyl substituents, progressing to the indole core fused with a prenyl-derived ring system, and the number of rings fused with the indole core determines their degree of complexity.

The extract of a solid rice culture of a mangrove-derived fungus Eurotium chevalieri KUFA 0006, isolated from a healthy twig of Rhizophora mucronata Poir., which was collected at Kung Krabaen Bay Royal Development Study Center, yielded two prenylated indoles, 3-carbaldehyde derivatives, namely, 2-(2-methyl-3-en-2-yl)-1H-indole-3-carbaldehyde (9) and 2-(2,2-dimethylcyclopropyl)-1H-indole-3-carbaldehyde (10) (Figure 4) [14], whereas an amide-containing eurotiumin D (11) and a diketopiperazine-containing eurotiumin C (12) (Figure 4) were obtained from the extract of a liquid culture of Eurotium sp. SCSIO F452, which was isolated from a South China Sea sediment sample [15]. 
<smiles>C=CC(C)(C)c1[nH]c2ccccc2c1C=O</smiles>

9<smiles>C=CC(C)(C)c1[nH]c2ccccc2c1/C=C1\NC(=O)C(=O)N(C)C1=O</smiles>

13<smiles>C=CC(C)(C)[C@]1(C[C@H]2NC(=O)[C@@]3(OCC)CCCN3C2=O)C(=O)Nc2c1ccc1c2C=CC(C)(C)O1</smiles>

16<smiles>C=CC(C)(C)[C@]1(C[C@@H]2NC(=O)[C@@H]3CCCN3C2=O)C(=O)Nc2cc3c(cc21)C=CC(C)(C)O3</smiles>

19<smiles>CC1(C)C[C@H]1c1[nH]c2ccccc2c1C=O</smiles>

10<smiles>C=CC(C)(C)c1[nH]c2ccccc2c1C(N)=O</smiles>

11<smiles></smiles>

12<smiles>C=CC(C)(C)c1[nH]c2ccc(C(O)C=C(C)C)c(CC=C(C)C)c2c1CC1NC(=O)C(C)NC1=O</smiles>

14<smiles>CC(C)=CCc1cccc2c3c(ccc12)[C@H](C(C)(C)C)NC(=O)[C@H](C)NC3=O</smiles>

15<smiles>C=CC(C)(C)C1NC(=O)[C@H]2CCCN2C1=O</smiles>

17<smiles>CC(=O)CC(=O)N1C(=O)[C@H]2c3c[nH]c4cccc(c34)C[C@H]2C1(C)C</smiles>

20<smiles></smiles>

18<smiles>C=CC(C)(C)[C@]12Nc3ccccc3[C@]1(O)C[C@H]1C(=O)N[C@@H](C)C(=O)N12</smiles>

21<smiles>[Z20]C(C)(C)[C@]12Nc3ccccc3[C@]1(O)C[C@H]1C(=O)N[C@@H](C)C(=O)N12</smiles><smiles>[Z9]=CC(C)(C)[C@]12Nc3c(ccc4c3C=CC(C)(C)O4)[C@@]1(O)C[C@@H]1C(=O)N3CCC[C@]3(O)C(=O)N12</smiles>

Figure 4. Structures of 9-23.

The diketopiperazine-containing indole alkaloids 11-methylneoechinulin E (13), variecolorin M (14), and (+)-variecolorin G (15) (Figure 4) were reported from a culture extract of Aspergillus sp. EGF 15-0-3 isolated from an unidentified soft coral that was collected from the South China Sea [16]. Co-cultivation of marine sediment-derived fungi Aspergillus sulphureus KMM 4640 and Isaria felina KMM 4639, on a solid rice medium, resulted in the isolation of a diketopiperazine-containing prenylated indole, 17-O-ethylnotoamide $\mathrm{M}$ (16) (Figure 4) belonging to a notoamide family [17]. The solid rice culture extract of Aspergillus versicolor, which was collected from the mud in the South China Sea, produced several prenylated indole alkaloids including the previously unreported asperversamides F-H (17-19) (Figure 4) featuring a pyrano[3,2-f]-indole. The structures of 17-19 were elucidated by extensive 1D and 2D NMR spectral analysis. Compound 17 is a C-17 epimer of the previously described dihydrocarneamide $\mathrm{A}$, whose absolute structure was determined by a single-crystal X-ray diffraction analysis [18]. The absolute configurations of C-11 and $\mathrm{C}-17$ in 17 were confirmed as $11 S, 17 R$ by comparison of the calculated and experimental optical rotations. On the other hand, the absolute configuration of the stereogenic carbon (C-17) in $\mathbf{1 8}$ was determined by comparison of the calculated and experimental ECD spectra while the absolute configurations of C-3, C-11, and C-11 in 19 were established by X-ray diffraction analysis using $\mathrm{CuK} \alpha$ radiation [18]. 
The ethyl acetate (EtOAc) extract of the culture of Pseudallescheria boydii F19-1, which was isolated from the inner tissue of a soft coral L. crassum, collected in the Hainan Sanya National Coral Reef Reserve, China, yielded a cyclopiazonic acid analogue, pseuboydone E (20) (Figure 4). The absolute configurations of C-4 and C-8 in 20 were established by comparison of the calculated and experimental ECD spectra [19].

The fungus Eurotium sp. SCSIO F452 also yielded tetracyclic 2,5-diketopiperazinecontaing prenylated indoles eurotiumins A (21) and B (22) (Figure 4). Both 21 and 22 feature a hexahydropyrrolo[2,3- $b$ ]indole skeleton (derived from a linkage between C-2 of the indole moiety and a nitrogen atom of a 1,4-diketopiperazine) and occurred as a pair of diastereomers, differing only in the absolute configurations of C-2 and C-3. The absolute configurations of the stereogenic carbons in $\mathbf{2 1}$ and 22 were established as $2 S, 3 R, 9 S, 12 S$ for 21 and $2 R, 3 S, 9 S, 12 S$ for 22 by comparison of the calculated and experimental ECD spectra [15].

Co-culture of $A$. sulphureus KMM 4640 with I. felina KMM 4639 also yielded 17hydroxynotoamide D (23) (Figure 4), consisting of a hexahydropyrrolo[2,3-b]indole skeleton, similar to that of $\mathbf{2 1}$ and 22, which is angularly fused with a 2,2-dimethylpyran ring. The absolute configurations of the stereogenic carbons in $\mathbf{2 3}$ were established by comparison of the calculated and experimental ECD spectra [17].

The EtOAc extract of a solid rice culture of the fungus Penicillium dimorphosporum KMM 4689 , isolated from soft coral samples that were collected from various points in the South China Sea, yielded seven unreported deoxyisoaustamide derivatives, namely $16 \alpha$-hydroxy-17 $\beta$ methoxydeoxydihydroisoaustamide (24), 16 $\beta$-hydroxy-17 $\alpha$-methoxydeoxydihydroisoaustamide (25), 16 $\alpha$-hydroxy-17 $\alpha$-methoxydeoxydihydroisoaustamide (26), 16,17-dihydroxydeoxydih ydroisoaustamide (27), 16 $\beta, 17 \alpha$-dihydroxydeoxydihydroisoaustamide (28), 16 $\alpha, 17 \alpha$-dihy droxydeoxydihydroisoaustamide (29), and 3 $\beta$-hydroxydeoxyisoaustamide (30) (Figure 5). The structures of the compounds of this group are characterized by a $6 / 5 / 8 / 6 / 5$ pentacyclic ring system whose indole and 1,4-diketopiperazine moieties are linked through the eight-membered hexahydroazocine ring. The structures of 24-30 were elucidated by extensive analysis of their 1D and 2D NMR spectra. The relative configurations of the stereogenic carbons in $\mathbf{2 4}$ were determined by single-crystal X-ray analysis whereas those of 25-30 were established by NOESY correlations. The absolute structure of $\mathbf{2 4}$ was based on its biogenic relationship with that of the previously described (+)-deoxyisoaustramide. The absolute configurations of the stereogenic carbons of the rest of the compounds were based on their biogenetic consideration as well as a comparison of their CD spectra [20].

The co-culture of the marine-derived A. sulphureus KMM 4640 with I. felina KMM 4639 also produced the unreported notoamides including 10-O-ethylsclerotiamide (31), 10-O-acetylsclerotiamide (32), and 10-O-ethylnotoamide R (33) (Figure 5) [17].

Aspergillus versicolor from the mud, collected in the South China Sea, also produced rare linearly fused dimethypyranoindoles containing an amine fused-imine pyrrole ring system, asperversamides A-E (34-38) (Figure 6). Compounds 34-36 and 38 each contain a rare anti bicyclo[2.2.2]diaza-octane ring, while 37 contains an analog syn ring. Moreover, 35/36 and 37/38 are pairs of C-3 and C-21 epimers, respectively. The relative configurations of all the compounds were established by NOESY correlations. In the case of 34, the absolute configurations of its stereogenic carbons were established by comparison of the calculated and experimental ECD spectra, while the absolute structure of 35 was established by the characteristic positive Cotton effect (CE) at $223 \mathrm{~nm}(+25.9)$ and negative $\mathrm{CE}$ at $242 \mathrm{~nm}(-28.6)$ in the experimental ECD spectrum and confirmed by a single-crystal $X$-ray diffraction analysis. The absolute configurations of the stereogenic carbons in $\mathbf{3 7}$ and 38 were established based on a similarity of their ECD spectra to that of the previously reported compound, (+)-6-epi-stephacidin A, and in the case of 37, its absolute structure was confirmed by X-ray analysis [18]. 
<smiles>[Z4]C1(C)C=CN2C(=O)[C@]3(OC)[C@@H](O)CCN3C(=O)[C@@H]2Cc2c1[nH]c1ccccc21</smiles>

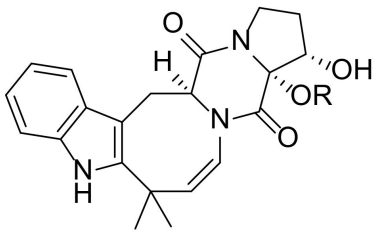

26, $\mathrm{R}=\mathrm{CH}_{3}$ 29, $\mathrm{R}=\mathrm{H}$<smiles>[R]C1CCN2C(=O)[C@@H]3Cc4c([nH]c5ccccc45)C(C)(C)C=CN3C(=O)[C@@]12C</smiles>

25, $\mathrm{R}=\mathrm{CH}_{3}$ 28, $\mathrm{R}=\mathrm{H}$

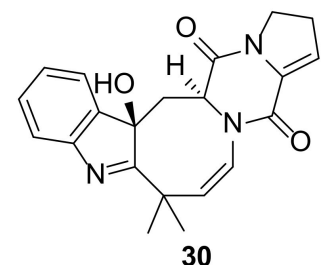

30<smiles>CC1(C)/C=C\N2C(=O)[C@@]3(O)[C@@H](O)CCN3C(=O)[C@@H]2Cc2c1[nH]c1ccccc21</smiles>

27

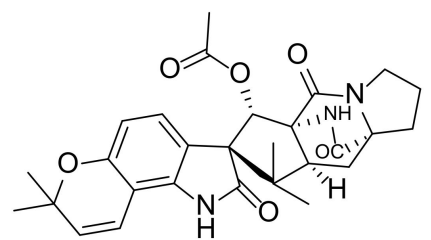

32

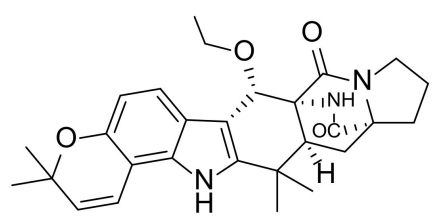

33

Figure 5. Structures of 24-33.

Brevianamides $X(39)$ and $Y(40)$ (Figure 6), two spiro 2-oxindole containing a bicyclo [2.2.2]diaza-octane ring system, were obtained from an acetone extract of the culture of a marine-derived fungus Penicillium brevicompactum DFFSCS025, which was isolated from a deep-sea sediment sample collected in the South China Sea in Hainan Province, China. The planar structures of both compounds were established by detailed analysis of 1D and 2D NMR spectra. NOESY correlations were used to determine the relative configurations of the stereogenic carbons of both compounds while their absolute configurations were established by a comparison of the calculated and experimental ECD spectra. Interestingly, 39 was found to be a diastereomer of the previously described (-)-depyranoversicolamide B [21].

The ethyl acetate extract of a culture of Aspergillus sp. YJ191021, isolated from a soil sample collected from the intertidal zone of Zhoushan, Zhejiang, China, yielded unreported prenylated diketopiperazine indole alkaloids, asperthins A-F (41-46) (Figure 6). Compounds 41-44 share the same feature consisting of a bicyclo[2.2.2]diaza-octane-containing indole $\mathrm{N}$ oxide, which is angularly fused with a dimethylpyran moiety, while 45 is a bicyclo[2.2.2]diazaoctane-containing spiro 2-oxindole, angularly fused with dimethyl pyran. Compound $\mathbf{4 6}$ features an angularly fused pyranoindole containing a diketopiperazine-fused amine pyrrole ring system. The planar structures of 41-46 were established by extensive analysis of 1D and 2D NMR spectra while the absolute configurations of their stereogenic carbons were determined by comparison of the calculated and experimental ECD spectra [22].

The EtOAc extract of a culture of Penicillium janthinellum HK1-6, which was isolated from a mangrove rhizosphere soil collected from the Dongzhaigang mangrove natural reserve in Hainan Island, yielded an unreported paraherquamide J (47) (Figure 6) whose structure consists of a prenylated indole featuring a spiro oxindole angularly fused with a dimethylpyran ring, which is connected with a bicyclo[2.2.2]diaza-octane-containing diketopiperazine-fused amine pyrrole ring system. The relative configurations of the stereogenic carbons in $\mathbf{4 7}$ were established by NOESY correlations while their absolute configurations were established by comparison of its ECD spectrum with that of man- 
grovamide A, a previously reported compound whose absolute structure was established by ECD data and X-ray analysis [23].

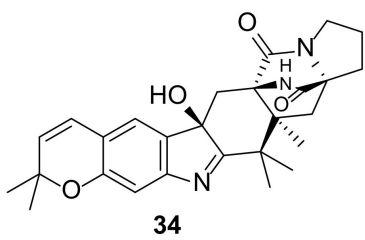

34

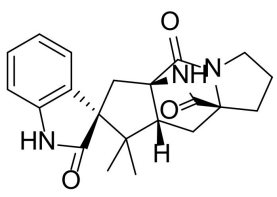

39

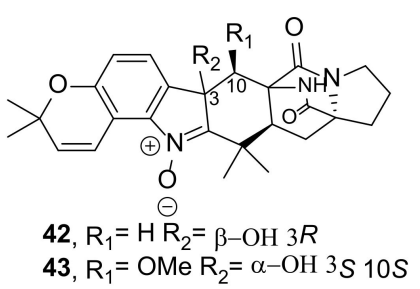

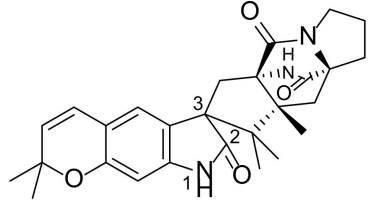

$35,3 S$

$36,3 R$

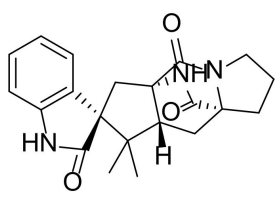

40

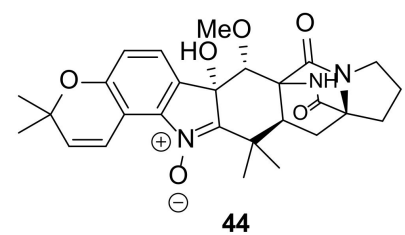

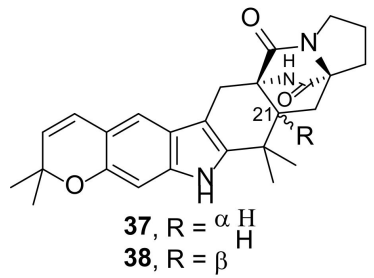

38, $R=\beta$

41

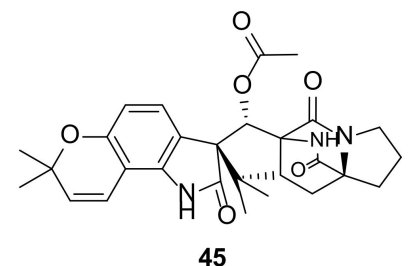

45<smiles>CC1(C)C=Cc2c(ccc3c2NC(CCO)C32C(=O)C[C@@H]3C(=O)N4CCCC4(O)C(=O)N3C2=O)O1</smiles>

46

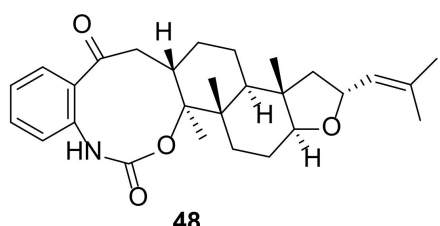

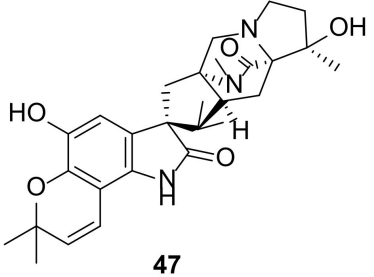

47<smiles>CC(=O)OCC(=O)OC1CCC2(C)C(CC[C@H]3Cc4c([nH]c5ccccc45)[C@@H]32)C1(C)CCC=C(C)C</smiles>

Figure 6. Structures of 34-49.

The EtOAc extract of a culture of Fusarium sp. L1 from a GPY liquid medium supplemented with L-Trp also produced fusaindoterpenes A (48) and B (49) (Figure 6). Compound 48 is a rearranged prenylated indole containing a 8,9-dihydro-1,3-oxazonine-2,6 $(3 H, 7 H)$-dione ring, while 49 features an indole fused with a substituted dodecahydro$1 H$-cyclopenta $[a]$ naphthalene ring system. The relative configurations of 48 and 49 were established by NOESY correlations. The absolute configurations of the estereogenic carbons of 48 were established by X-ray analysis, while those of 49 were established by a comparison of the calculated and experimental ECD spectra [7].

The EtOAc extract of a fermentation broth of Penicillium sp. KFD28, isolated from a bivalve mollusc, Meretrix lusoria, which was collected from Haikou Bay, China, furnished four indolediterpenoids, named penerpenes A-D (50-53) (Figure 7). Compound 50 features a hexacyclic ring system comprising 1,2-dihydro-2' $H$-spiro [3,1-benzoxazine$4,1^{\prime}$-cyclopentan]-2'-one fused with a decalin ring system, while 51-53 share a common feature, having an indole ring system fused with a cyclopentane ring of the dodecahydro- 
$1 H$-cyclopenta[a]naphthalene ring system. However, the structure of $\mathbf{5 1}$ is unique since it has a pyridine ring fused with a decalin moiety. The planar structures of $\mathbf{5 0 - 5 3}$ were elucidated by extensive analysis of their 1D and 2D NMR data. The absolute configurations of the stereogenic carbons in $\mathbf{5 0}$ and $\mathbf{5 1}$ were established by comparison of the calculated and experimental ECD spectra while only the relative configurations of $\mathbf{5 2}$ were established by ROESY correlations. On the other hand, the absolute configurations of the stereogenic carbons in 53 were established using the ECD exciton chirality models [24]. The presence of a spiro 1,4-dihydro- $2 \mathrm{H}-3,1$ benzoxazine ring in $\mathbf{5 0}$ and the presence of a pyridine ring in 51, together with a new carbon skeleton in $\mathbf{5 2}$ and 53, led Kong et al. [24] to propose the biosynthesis of these compounds as a degradation and rearrangement of the carbon skeletons of paxilline-type indole terpenoids, paxilline (I) and emindole SB (VI), which were co-isolated with $\mathbf{5 0 - 5 3 . ~}$

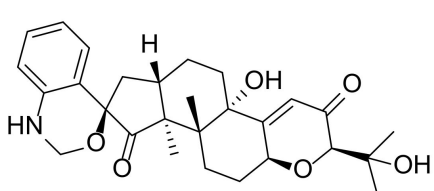

50<smiles>C[C@]12CC[C@@H]3Cc4c([nH]c5ccccc45)[C@H]3C1(O)CCC1OC(=O)C=C12</smiles>

53<smiles>CC(C)(O)C1OC(=O)C=C2C(CC[C@@]3(O)C2CC[C@H]2Cc4c([nH]c5ccccc45)[C@H]23)O1</smiles>

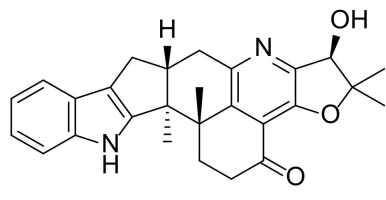

51

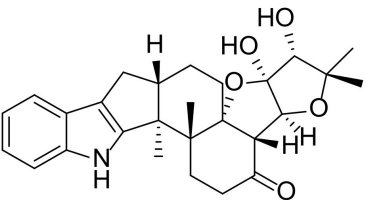

54

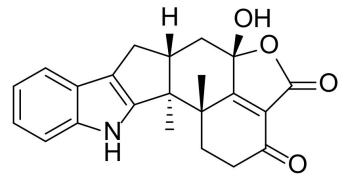

52<smiles>C[C@]12CC[C@H]3OCC(=O)C=C3[C@@]1(O)CC[C@@H]1Cc3c([nH]c4ccccc34)[C@H]12</smiles>

55

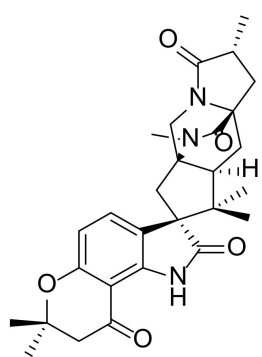

59

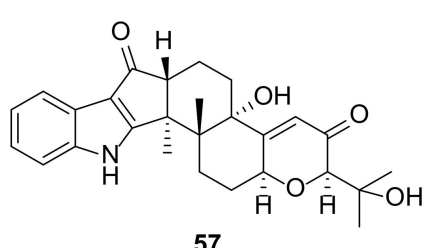

57<smiles>CC(C)(O)C1OC2CCC3(C(=O)O)C(C(=O)O)CC[C@@H](CC(=O)c4ccccc4N)C3(O)C2=CC1=O</smiles>

58

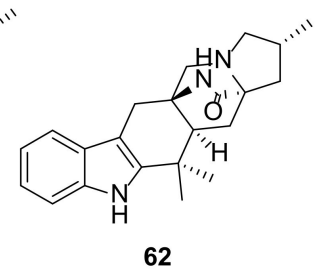

62

Figure 7. Structures of 50-62.

Compounds 50, 52, and 53 are hypothesized to derive from paxilline (I) (Figure 8a).

$\mathrm{N}$-methylation and oxidation of the indole portion of paxilline (I) yields $\mathbf{V}$ with $\mathrm{N}$ hydroxymethyl and an epoxide between C-8 and C-9. Nucleophillic substitution of C-8 by $\mathrm{OH}-28$ with a concomitant opening of the epoxide ring and a cleavage of C-9-N leads to thee formation of a spiro 1,4-dihydro-2H-3,1 benzoxazine ring in 50 . On the other hand, Baeyer-Villinger oxidation of I gives II, with a 1,3-dioxepan-4-one ring, and III, with a 1,4-dioxepan-5-one ring. Rearrangement of the 1,3-dioxepan-4-one ring in II yields 53, while ring cleavage, dehydration, and oxidation of III gives IV. Lactonization of IV yielded 52 (Figure 8a). 
of 39

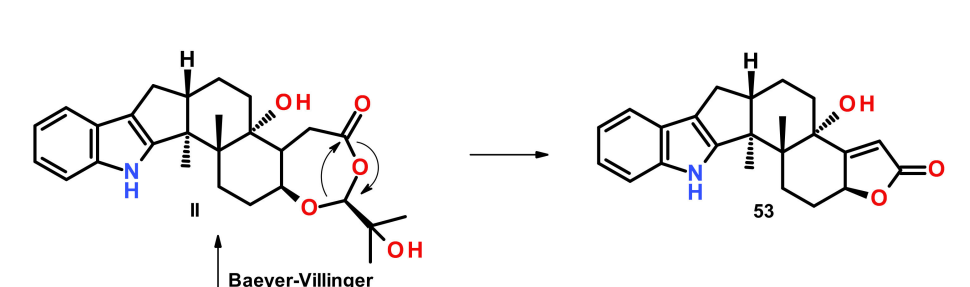

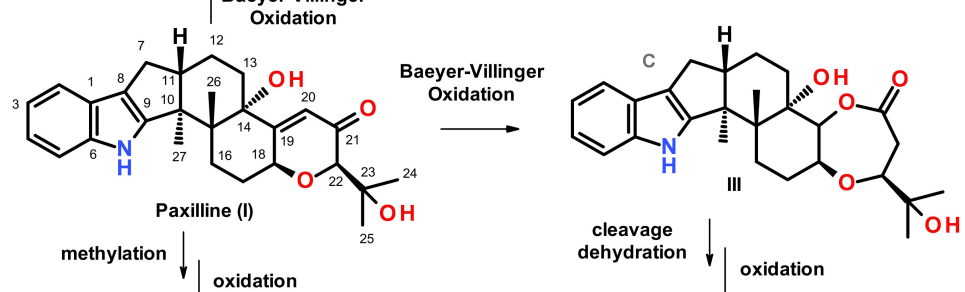

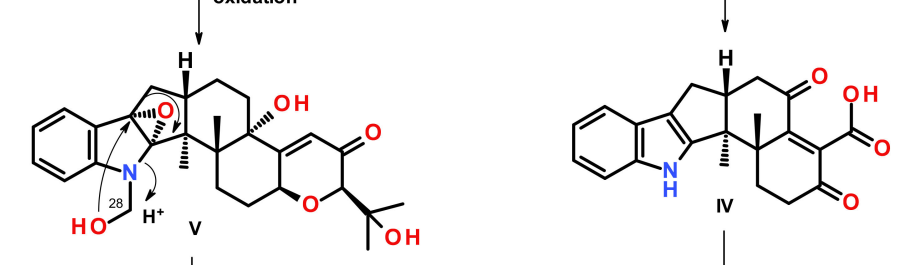

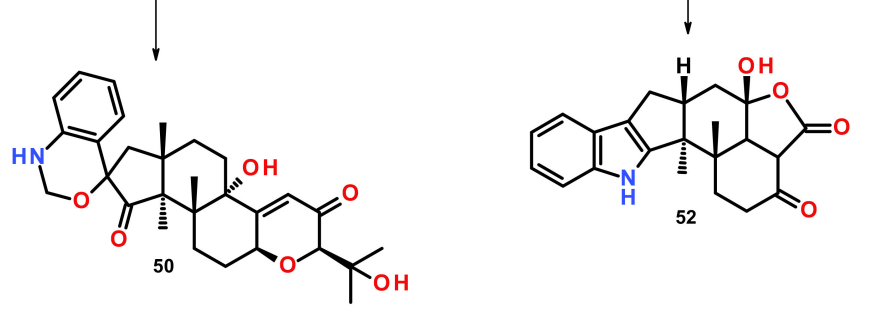

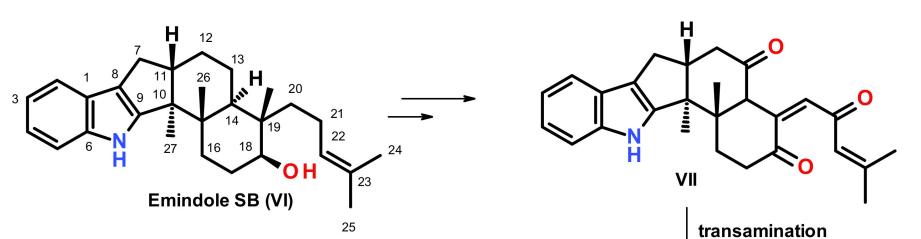

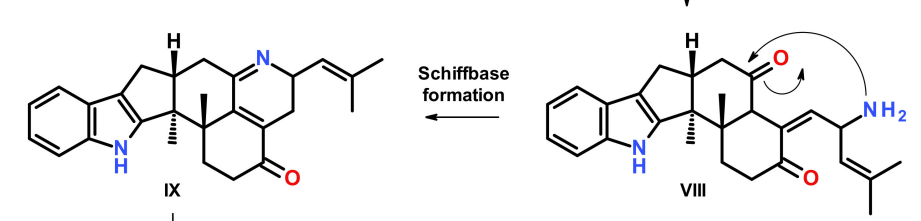

$$
\begin{aligned}
& \text { ontext - ontwet } \\
& \text { ostione }
\end{aligned}
$$


Emindole SB (VI) was proposed to be a biosynthetic precursor of 51. Oxidation of VI gives rise to VII, followed by transamination to give VIII. Nucleophillic addition of the ketone at $\mathrm{C}-13$ by $\mathrm{NH}_{2}-21$ yields an imine in IX. Oxidation and epoxidation of IX gives $\mathbf{X}$, which, after enolization, yields XI. Nucleophillic substitution on C-23 of the epoxide by $\mathrm{OH}-18$ leads to a formation of a 3-hydroxydihydropyran ring in $\mathbf{5 1}$ (Figure 8b).

Further investigation of the same fungal extract by the same research group led to the isolation of an additional five paxilline-type indolediterpenoids, penerpenes E-I (54-58) (Figure 7) [25]. Compound 54 has a unique skeleton comprising a hexahydrofuro[3,2$b$ ]furan-containing heptacyclic ring system, while 55 corresponds to a loss of three carbons of the side chain of paxilline by the retro-aldol reaction. Compound 56 contains a 1,3dioxepan-4-one ring, corresponding to a Baeyer-Villiger oxidation product of paxilline. Compound 58 derived from the cleavage of a pyrrole ring of the indole moiety. The planar structures of 54-58 were established by extensive analysis of 1D and 2D NMR spectra as well as high resolution mass spectrometry (HRMS). The absolute configurations of the stereogenic carbons in 54 were determined by a comparison of the calculated and experimental ECD spectra while the absolute structures of 55-57 were established by a comparison of their ECD curves with that of paxilline. In contrast, the absolute configurations of the stereogenic carbons in $\mathbf{5 8}$ were established based on a biogenic consideration [25].

Tao et al. reported the isolation of four undescribed prenylated indoles, mangrovamides D-G (59-62) (Figure 7) from the culture extract of Penicillium sp. SCSIO041218, which was obtained from a mangrove sediment in Sanya, China. All compounds feature a 5,8diazatricyclo[5,2,2, $\left.0^{1,5}\right]$ undecan-9-one moiety that incorporates proline (Pro). In particular, 59 and 60 contain a spiro 2-oxindole, similar to that found in 35, 36, 39, and 40 (Figure 6). The structures of 59-62 were established by HRMS and interpretation of 1D and 2D data. The relative configurations of the stereogenic carbons in $\mathbf{5 9}$ were established by NOESY correlations and comparison of its ECD profile with that of mangrovamide A, which was previously isolated from the same fungus, and whose absolute structure has been established by a single-crystal X-ray analysis. The stereostructures of 60-62 were determined based on a comparison of their ECD profiles with that of 59 [26].

Ascandinines A-D (63-66) (Figure 9), paxiline-like indolediterpenoids, were obtained from the culture of Aspergillus candidus HDN15-152, which was associated with an unidentified Antarctic sponge. Compound 63 has an unprecedented 7-chloroindole-substituted 6/6/6/6/6 pentacyclic skeleton with a 2-oxabicyclo[2.2.2]octan-3-ol motif, which is structurally derived from a cleavage of the C-17 and C-18 bond in the paxilline-like indolediterpenoids. On the other hand, 64-66 also share the same 2-oxabicyclo[2.2.2]octan-3-ol motif, however, they have a heptacyclic skeleton comprising the indole ring system fused with the dodecahydro- $1 H$-cyclopenta[a]naphthalene ring system. The difference between $\mathbf{6 4}$ and $\mathbf{6 5}$ is the presence of a chlorine substituent in the benzene ring of the indole moiety in $\mathbf{6 4}$. The relative configurations of 63-66 were determined by analysis of NOESY correlations and the absolute configurations of their stereogenic carbons were established by comparison of the calculated and experimental ECD spectra as well as by biogenetic considerations [27].

Asperindoles A-D (67-70) (Figure 9) are indolediterpenes with the same scaffold as those of 64-66. Compounds 67-70 were obtained from the solid rice culture extract of Aspergillus sp. KMM4676, which was isolated from an unidentified colonial ascidian in Shikotan Island, Pacific Ocean. It is interesting to note that both 67 and 69 are chlorinated analogues of 68 and 70, similar to 63 and 65 . Although chlorinated indolediterpenes are not very common, the occurrence of 63,67 , and 69 demonstrates that some marine-derived Aspergillus species have the capacity to introduce a chlorine atom to the benzene ring of the indole moiety. The structures of 67-70 were elucidated by extensive analysis of $1 \mathrm{D}$ and $2 \mathrm{D}$ spectral data. The relative configurations of the stereogenic carbons in $\mathbf{7 0}$ were established by NOESY correlations, however, their absolute configurations were proposed based on biogenetic consideration. The relative configurations of the stereogenic carbons in 69 were established by ROESY correlations and their absolute configurations were determined based on a comparison of its experimental ECD spectrum with that of 67 [28]. 

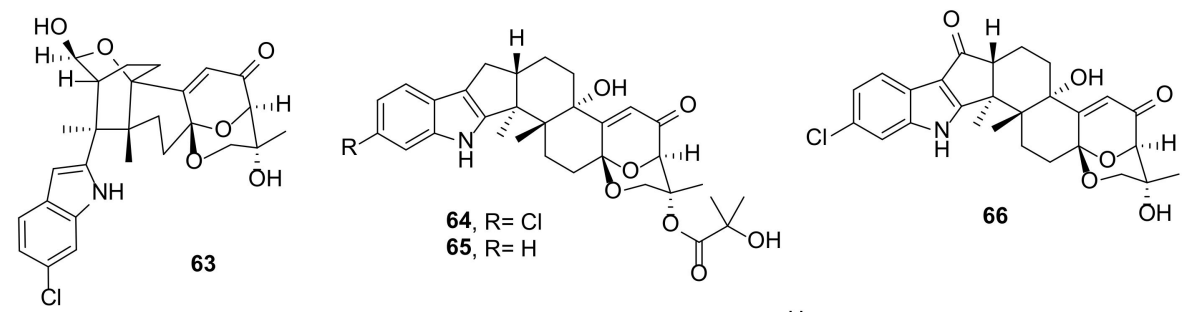

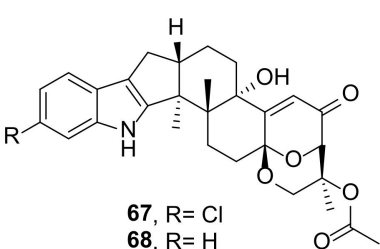

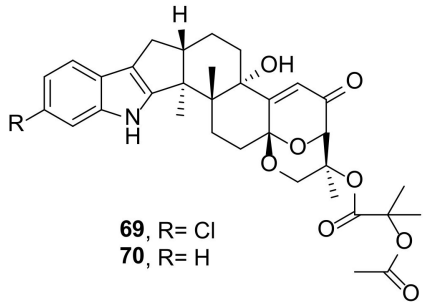

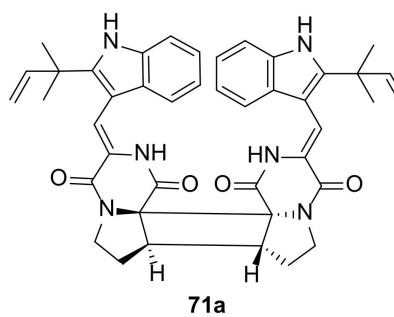

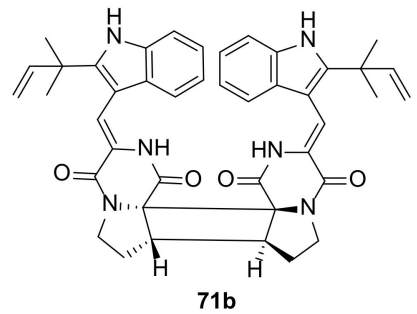<smiles>C=CC(C)(C)c1[nH]c2c(-c3c(O)ccc4c(C[C@H]5NC(=O)[C@H]6CCCN6C5=O)c(C(C)(C)C=C)[nH]c34)c(O)ccc2c1C[C@@H]1NC(=O)[C@@H]2CCCN2C1=O</smiles>

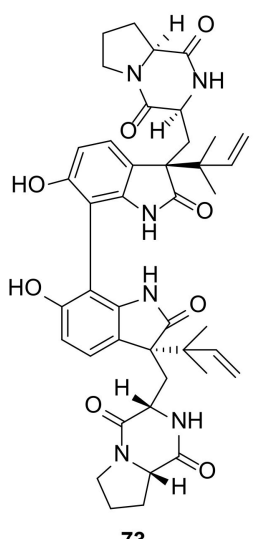

Figure 9. Structures of 63-73.

A pair of enantiomeric diketopiperazine prenylated indole alkaloid dimers, (-)- and (+)-asperginulin A (71a and 71b) (Figure 9), was obtained as a racemic mixture from the EtOAc extract from the wheat cultures of an endophytic fungus, Aspergillus sp. SK-28A, which was isolated from the leaves of the mangrove plant Kandelia candel from the South China Sea. The structure elucidation of the compounds was carried out by a combination of extensive 1D and 2D NMR spectral analysis and X-ray diffraction analysis to obtain a planar structure and relative configurations of the compounds. By using a HPLC equipped with a chiral INA column, it was possible to separate the two enantiomers. Both enantiomers were separately recrystallized to obtain a suitable crystal for X-ray diffraction analysis using $\mathrm{CuK} \alpha$ radiation to obtain crystal structures with good Flack parameters, thus allowing the determination of the absolute configurations of the stereogenic carbons of each enantiomer. The absolute configurations were also confirmed by a comparison of the calculated and experimental ECD spectra. It is interesting to note that the indole nucleus is substituted by a reverse prenyl group and a dimerization occurs by intermolecular cycloaddition of the hexahydropyrrolo [1,2-a]1,4-diketopiperazine moieties, forming a rare 6/5/4/5/6 pentacyclic skeleton [29]. 
The EtOAc extract of the rice culture of Aspergillus austroafricanus Y32-2, isolated from a seawater sample, which was collected from the Indian Ocean at the depth of $30 \mathrm{~m}$, yielded two diketopiperazine-containing prenylated indole dimers, di-6-hydroxydeoxybrevianamide E (72) and dinotoamide J (73) (Figure 9). The structures of the compounds were elucidated by extensive analysis of 1D and 2D NMR spectral data together with HRMS. The absolute configurations of their stereogenic carbons were established by a comparison of thee calculated and experimental ECD spectra. It is interesting to note that, unlike $\mathbf{7 1 b} / \mathbf{7 1 b}$, both 72 and 73 were derived from dimerization of the activated carbon of the benzene ring of the indole moieties. However, there was a difference between the 72 and 73 resides in the indole nucleus. While 72 contains an indole nucleus substituted with a reverse prenyl group at C-2, 73 contains an oxindole whose reverse prenyl substituent is on C-3 [30].

Bis-/Tris-Indoles

Bis-and tris-indoles can be derived either from two (or three) direct linkage between the same indole monomers to give homodimers (or homotrimers) or different indole monomers to give heterodimers (or heterotrimers). Moreover, these indole monomers can also link together through different side chains.

Fusariumindole B (74), a bis-indole derivative comprising two indole moieties linked through C-2 and C-2', and fusariumindole A (75) (Figure 10) were also isolated from the extract of the marine-derived Fusarium sp. L1, cultured in L-Trp-supplemented GYP medium. Compound 74 comprises two indole moieties linked through C-2 and C-2', while in 75 , both indole moieties are linked together not directly but by an ethyl acetate ester through C-3 of the indole ring [7].

Shaker et al. [31] described the isolation of a pair of bis-indole alkaloid enantiomers (+)- and (-)-fusaspoid A (76a and 76b) (Figure 10) from the extract of a marine-derived fungus Fusarium sp. XBB-9, obtained from the Hainan Sanya National Coral Reef Reserve, China, and cultured in a GYP medium supplemented with Phe and Trp. Compounds $\mathbf{7 6 a}$ and $\mathbf{7 6 b}$ were isolated as a racemic mixture whose planar structure was established by extensive 1D and 2D NMR spectral analysis as 3-(3'-methyleneindole)hydroxymethyl-2-oxindole. The racemic mixture was separated by the HPLC chiral column into 76a and 76b. The stereostructure of 76a was established by X-ray analysis as (3S)-(3'-methyleneindole)-hydroxymethyl-2-oxindole, whereas $\mathbf{7 6} \mathbf{b}$ was identified as (3R)( $3^{\prime}$-methyleneindole)-hydroxymethyl-2-oxindole through comparison of its CD spectrum with that of $\mathbf{7 6 a}$.

By using GYP medium supplemented with L-Trp, L-Phe, L-Met, and L-Thr, two previously unreported bis-indole alkaloids, pseudboindoles A (77) and B (78) (Figure 10), were obtained from a culture broth of the fungus Pseudallescheria boydii F44-1, isolated from the inner tissue of a soft coral Sarcophyton sp., which was collected from the Hainan Sanya National Coral Reef Reserve, China. The planar structure of both compounds were elucidated based on HRESIMS and 1D and 2D NMR data. Compound 77 was identified as 1,3-di(1Hindol-3-yl)propan-2-ol, whereas 78 was identified as 3,3' [3-(methylsulfinyl)propane-1,1diyl]bis(1H-indole). However, the absolute configuration of the stereogenic carbon in both compounds was not determined [32].

A diketopiperazine derivative, fellutanine A epoxide (79), was isolated from the culture extract of a marine sponge-associated fungus Neosartorya glabra KUFA 0702. The structures of 79 were established based on extensive 1D and 2D NMR spectral analysis. The absolute configurations of the stereogenic carbons of the epoxide ring (C-2' and C- $\left.3^{\prime}\right)$ were determined based on NOESY correlations, in conjunction with conformational search, molecular dynamics, and ab initio molecular modeling [13].

The EtOAc extract of the culture of Aspergillus candidus KUFA0062, isolated from a marine sponge Epipolasis sp., which was collected by scuba diving at a depth of 15-20 $\mathrm{m}$ from the coral reef at Similan Island National Park, Southern Thailand, produced a bis-indolyl benzenoid analogue, candidusin D (80) [33]. 
<smiles>COC(=O)Cc1c(-c2cc3ccccc3[nH]2)[nH]c2ccccc12</smiles>

74<smiles>O=C1Nc2ccccc2C1CCO</smiles>
$76 b$<smiles>O=C(Cc1c[nH]c2ccccc12)OCCc1c[nH]c2ccccc12</smiles>

75<smiles>OC(Cc1c[nH]c2ccccc12)Cc1c[nH]c2ccccc12</smiles>

77<smiles>O=C1Nc2ccccc2C1CCO</smiles>

76a<smiles>CS(=O)CCC(c1c[nH]c2ccccc12)c1c[nH]c2ccccc12</smiles>

78<smiles>O=C1NC(Cc2c[nH]c3ccccc23)C(=O)NC1Cc1c[nH]c2ccccc12</smiles><smiles></smiles>

80

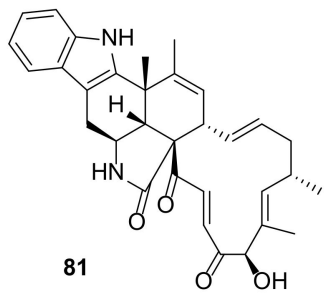

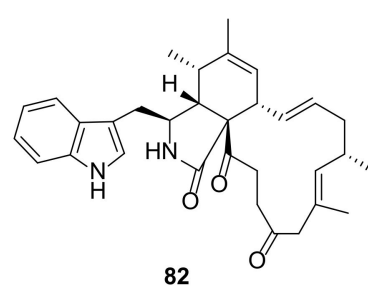

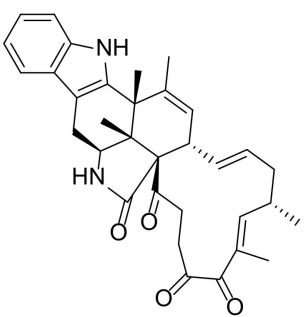

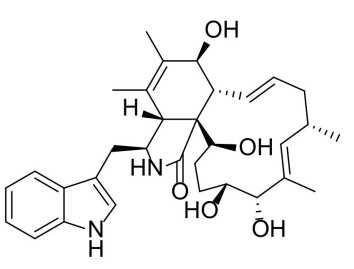

84

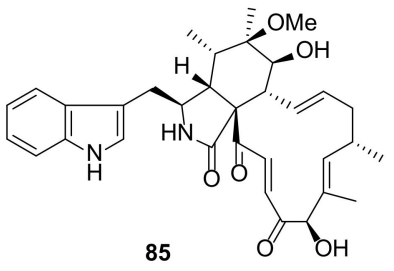

85

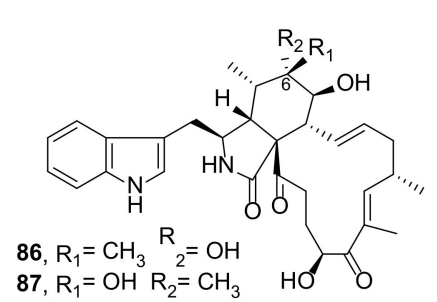

Figure 10. Structures of 74-87.

The culture extract of an endophytic fungus, Penicillium chrysogenum V11, isolated from the vein of a semi-mangrove tree, Myoporum bontioides A. Gray, which was collected in Leizhou Peninsula, China, furnished chaetoglobosin alkaloids, penochalasins I (81), and J (82) (Figure 10). Compound 81 features a 6/5/6/5/6/13 hexacyclic ring system, while 82 consists of two indole moieties, one of which is fused with a 13-membered macrocyclic ring. The structures of both compounds were elucidated by a combination of HRMS with 1D and 2D NMR spectral analysis. The absolute configurations of the stereogenic carbons were established by comparison of the calculated and experimental ECD spectra [34]. Further study of the same fungus led to the isolation of another chaetoglobosin indole alkaloid with a $6 / 5 / 6 / 5 / 6 / 13$ hexacyclic fused ring system, named penochalasin $\mathrm{K}(83)$. The only difference between $\mathbf{8 1}$ and $\mathbf{8 3}$ is that the hydroxyl group of the 13-membered macrocyclic ring in 81 is replaced by a ketone function in 83 [35].

Cytoglobosin X (84) (Figure 10) was obtained from a culture extract of the endophytic fungus Chaetomium globosum strain E-C-2, which was isolated from the surface muscle of a sea cucumber, Apostichopus japonicus, collected from Chengshantou Island, Weihai City, the Yellow Sea, China [36]. The culture of a coral-associated fungus C. globosum C2F17, isolated from a coral Pocillopora damicornis, which was collected from the seashore near Sanya 
Bay, Hainan Province, China, yielded a cytochalasan alkaloid 6-O-methylchaetoglobosin $\mathrm{Q}$ (85) (Figure 10). The structure of $\mathbf{8 5}$ was determined using extensive spectroscopic analysis whereas the configurations of its stereogenic carbons were determined through a comparison of the calculated and experimental ECD spectra. The authors speculated that 85 was probably an artifact derived from acidic solvolysis of the previously reported epoxide of chaetoglobosin A [37]. Cytoglobosin H (86) and its C-6 epimer, cytoglobosins I (87) (Figure 10) were obtained from the extract of a solid rice culture of C. globosum, which was isolated from deep-sea sediments collected from the Indian Ocean. The structures of both compounds were established by extensive 1D and 2D NMR spectral analysis. Their relative configurations were determined by ROESY correlations, however, the absolute configurations of their stereogenic carbons were not determined [38].

\section{Annelated Indoles}

Two methylsulfinyldiketopiperazine-containing annelated indoles, dichocerazines A (88) and B (89) (Figure 11), were isolated from the culture extract from a soft coral-associated fungus Dichotomomyces cejpii F31-1, cultured in a GYP medium supplemented with L-Trp and L-Phe. The structures of $\mathbf{8 8}$ and $\mathbf{8 9}$ were elucidated by the analysis of 1D and 2D NMR spectra as well as HRMS data. Compound $\mathbf{8 8}$ was isolated as a racemate since it showed no optical rotation, and an effort to separate the enantiomers by a HPLC equipped with a Chiralcel OD column was not successful. In contrast, $\mathbf{8 9}$ was isolated as a pure compound and the absolute configurations of its stereogenic carbons were established by comparison of the calculated and experimental ECD spectra [8]. Structurally, 88 was derived from a condensation of Trp and Gly whereas $\mathbf{8 9}$ was derived from a condensation of Trp and Ser, and methylsulfinyl substituents were introduced in a later stage to the carbon adjacent to the carbonyl function.

A diketopiperazine-containing oxindole alkaloid, raistrickindole A (90) (Figure 11), was obtained from the EtOAc extract from a solid rice culture of Penicillium raistrickii IMB17-034, which was isolated from marine sediments collected in a mangrove swamp in Sanya, Hainan Province, China. Structurally, $\mathbf{9 0}$ was derived from a condensation of Trp and Phe, therefore the absolute configuration of L-Phe was established by the advanced Marfey's analysis. The absolute configurations of the rest of the stereogenic carbons were determined by comparison of the calculated and experimental ECD spectra [39].

The EtOAc extract of a culture broth of Aspergillus sp. HNMF114, isolated from a bivalve mollusk Sanguinolaria chinensis, which was collected from Haikou Bay, Hainan Province, China, furnished aspertoryadins F (91) and G (92) (Figure 11). Compounds 91 and 92 contain 2-indolone moiety linked to a quinazolinone ring system through a five-membered spiro lactone. The planar structures of the compounds were elucidated by analysis of 1D and 2D spectra as well as HRMS data. However, the ECD spectra of 91 and 92 are mirror images through the Cotton effects (CEs) around 210 and $230 \mathrm{~nm}$. According to the ECD exciton coupling rule, the absolute configurations of C-3 and C-12 of 91 and 92 were determined as $3 S, 12 S$, and $3 R, 12 R$, respectively. However, the absolute configuration of the stereogenic carbon in the side chain of the quinazolinone moiety was the same [40].

Fumigatoside E (93) (Figure 11), whose indole moiety is fused with a pyrazinone ring of the pyrazinoquinazolinone moiety, was obtained from a culture extract of Aspergillus fumigatus SCSIO 41012 isolated from deep-sea sediments that were collected from the Indian Ocean. The planar structure of the compound was elucidated by HRMS and extensive 1D and 2D NMR spectral analysis. The absolute configurations of its stereogenic carbons were established as $3 R, 14 R$ by comparison of the calculated and experimental ECD spectra [41].

Scedapin E (94) (Figure 11), an indole alkaloid comprising an oxindole moiety linked to a pyrazinoquinazolinone moiety via a spiro pyran ring, was isolated from the extract of a marine-derived fungus Scedosporium apiospermum F41-1, cultured in a GYP medium supplemented with L-Trp, L-Phe, L-Thr, and D,L-Met. The planar structure of $\mathbf{9 4}$ was elucidated by HRMS and 1D and 2D NMR spectral analysis. The stereostructure of 94 was established by a single-crystal X-ray analysis [12]. 
<smiles>CSC1C(=O)n2c(cc3ccccc32)C(=O)N1C</smiles>

88<smiles>CS[C@]1(CO)C(=O)N(C)[C@]2(SC)C[C@@]3(O)C=CC(=O)[C@H](OC(C)=O)[C@@H]3N2C1=O</smiles>

89<smiles>C[C@]12Nc3ccccc3[C@@]1(O)C[C@@H]1C(=O)N[C@H](Cc3ccccc3)C(=O)N1O2</smiles>

90<smiles>CC(=O)OC(C(C)C)C(C(C)C)n1c(C2C(=O)Nc3ccccc32)nc2ccccc2c1=O</smiles>

91

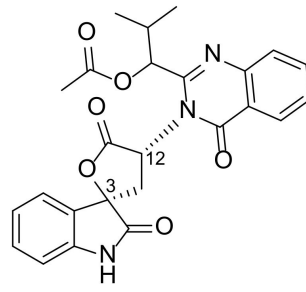

92<smiles>CC1NC2N(C1=O)c1ccccc1C2(O)C[C@@H](C(=O)O)n1cnc2ccccc2c1=O</smiles>

95

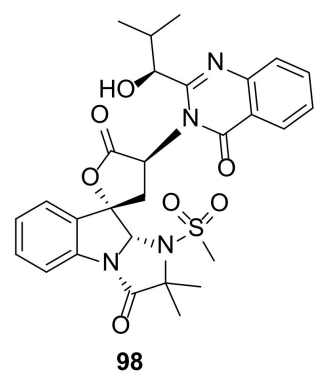

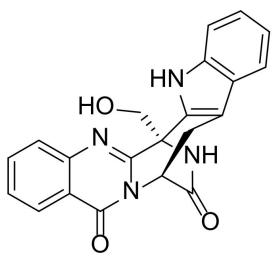

93<smiles>CC(C)[C@H](O)c1nc2ccccc2c(=O)n1[C@H]1C[C@@]2(OC1=O)c1ccccc1N1C(=O)[C@@H](C)N[C@H]12</smiles>

96

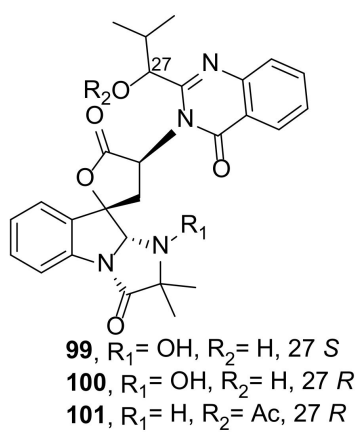<smiles>CC1(O)C(=O)c2nc3ccccc3c(=O)n2CC1C1C(=O)Nc2ccccc21</smiles>

94<smiles>CC(C)[C@H](O)c1nc2ccccc2c(=O)n1[C@H]1C[C@@]2(OC1=O)c1ccccc1N1C(=O)C(C)(C)N(S(C)(=O)=O)[C@@H]12</smiles><smiles>CCC(=O)OC(c1nc2ccccc2c(=O)n1[C@H]1C[C@@]2(OC1=O)c1ccccc1N1C(=O)C(C)(C)N(O)[C@H]12)C(C)C</smiles>

Figure 11. Structures of 88-102.

Fumigatoside F (95) (Figure 11), an indole alkaloid comprising a 6-5-5-imidazoindolone ring linked to a quinazolinone ring system via an ethylene bridge, was obtained from a culture extract of $A$. fumigatus SCSIO 41012, isolated from deep-sea sediments that were collected from the Indian Ocean. The planar structure of the compound was established by 1D and 2D NMR spectral analysis as well as HRMS data. The proton chemical shift values suggest that the structure of $\mathbf{9 5}$ was derived from the opening of the lactone ring in tryptoquivaline $\mathrm{E}$, however, the absolute configurations of its stereogenic carbons were not determined [41].

Aspertoryadins I (96) and J (97) (Figure 11) were isolated from the culture extract of the fungus Aspergillus sp. HNMF114, obtained from a mollusk Sanguinolaria chinensis. These alkaloids comprise an indole moiety fused with an imidazolone ring to form a 6-5-5imidazoindolone ring system, which is linked to a quinazolinone ring system through a five-membered spiro lactone such as in tryptoquivalines [42]. Aspertoryadins A-E (98-102) (Figure 11), which also contain an imidazoindolone moiety linked to a quinazolinone ring system through a five-membered spiro lactone, were also isolated from the same fungus. Compound 98 has an unusual methylsulfonyl group attached to the nitrogen atom of 
the imidazolone moiety while the rest of the compounds, except for 101, has a hydroxyl group on this nitrogen atom. The stereostructure of $\mathbf{9 8}$ was established by $\mathrm{X}$-ray analysis and was confirmed by the comparison of the calculated and experimental ECD spectra. Compounds $\mathbf{9 9}$ and $\mathbf{1 0 0}$ are C-27 epimers whose absolute configurations of C-27 were determined by comparison of their C-27 chemical shift values with that of 98 . The relative configurations of $\mathbf{1 0 1}$ and $\mathbf{1 0 2}$ were established based on ROESY correlations, however, the absolute configurations of their stereogenic carbons were not determined [40].

Scetryptoquivaline A (103), an $\mathrm{N}$-methylsulfonyl imidazoindolone connected to quinazolinone moiety through a five-membered lactone, and scequinadoline I (104) (Figure 12), an imidazoindolone connected to an isopropyl pyrazinoquinazolinone moiety through a methylene bridge (Figure 12), were also isolated from the culture extract of a coralassociated fungus Scedosporium apiospermum F41-1 [11] while aspertoryadin H (105), another imidazoindolone connected to isopropylquinazolinone moiety through a methylene bridge, was also isolated from a mollusk-associated fungus Aspergillus sp. HNMF114 [42] Scequinadolines A-F (106-111) (Figure 12), comprising an imidazoindolone connected to an isopropylpyrazinoquinazolinone moiety through a methylene bridge, and scedapins A-D (112-115) (Figure 12), whose imidazoindolone moiety is connected to a pyrazinoquinazolinone through a spiro tetrahydrofuran, were also isolated from the culture extract of a soft coral-associated fungus S. apiospermum F41-1 [12].

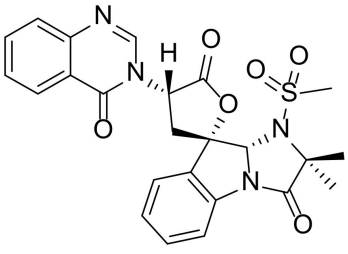

103

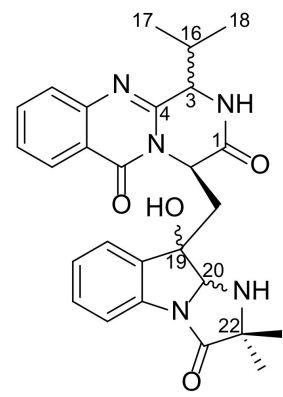

106, (3S,14R,19R,20S) 107, (3S,14R,19R,20R)<smiles>CC(C)=C1NC(=O)[C@H](CC2(O)c3ccccc3N3C(=O)C(C)(C)N[C@@H]32)n2c1nc1ccccc1c2=O</smiles>

111<smiles>CC1(C)N[C@H]2N(C1=O)c1ccccc1[C@@]2(O)C[C@@H]1C(=O)N[C@](O)(C(C)(C)C)c2nc3ccccc3c(=O)n21</smiles>

104<smiles>CC(C)[C@H]1NC(=O)[C@H]2C[C@@]3(O)c4nc5ccccc5c(=O)n4[C@@H](N[C@H](C(C)C)[C@H]3C(C)C)c3ccccc3N2C1=O</smiles>

108<smiles></smiles>

105<smiles>[R]C1([R2])N[C@H]2N(C(=O)C2(O)C[C@@H]2C(=O)NC(=C(C)C)c3nc4ccccc4c(=O)n32)c2ccccc21</smiles>

109, ${ }_{\mathrm{R} 1}^{\mathrm{R}}=\mathrm{CH}_{2} \mathrm{Me}, \mathrm{R}_{2}=\mathrm{H}$

110, ${ }_{1}=\mathrm{CH}(\mathrm{Me})_{2}, \mathrm{R}_{2}=\mathrm{H}$

Figure 12. Structures of 103-116.

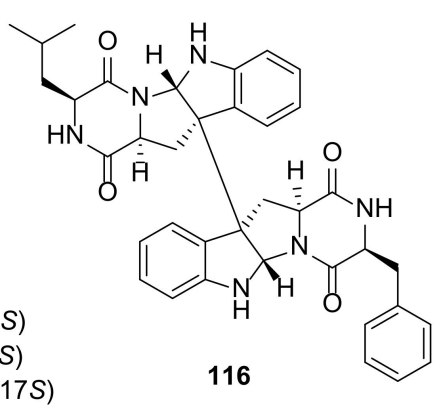

116
113, $\mathrm{R}^{1}=\mathrm{H}, \mathrm{R}_{2}=\mathrm{H}$; $(1 S, 14 S, 16 S, 17 R, 19 S)$

114, $\mathrm{R}^{1}=\mathrm{SO}_{2} \mathrm{Me}, \mathrm{R}_{2}=\mathrm{Me} ;(1 R, 14 R, 16 \mathrm{~S}, 17 \mathrm{~S})$

$115, \quad{ }_{1}=\mathrm{H}, \mathrm{R}_{2}=\mathrm{Me} ;(1 S, 14 S, 16 S, 17 R)$ 
A heterodimer of an indolodiketopiperazine derivative, named SF5280-415 (116) (Figure 12) was obtained from the culture extract of Aspergillus sp. SF-5280, isolated from an unidentified sponge that was collected at Cheju Island, Korea. The structure of the compound was established by a combination of HRMS and 1D and 2D NMR spectral analysis. The configurations of the amino acid constituents, Phe and Leu, were determined by Mafrey's method while the relative configurations of the stereogenic centers of the diketopiperazine ring and C-2 and C-3 of the indole moiety were established by observation of NOESY correlations and compared with those of the previously described compounds (WIN 64745 and ditryptophenaline) [43].

\subsubsection{Marine-Derived Bacteria}

In comparison with marine-derived fungi, marine-derived bacteria are less prolific in terms of indole alkaloid production. Most of the indole alkaloids discovered in this period are simple, bis-, and tris-indoles.

\section{Simple Indoles}

A simple indole alkaloid comprising an oxindole with an amide side chain, named bacilsubteramide A (117) (Figure 13), was isolated from an EtOAc extract of the culture of Bacillus subterraneus 11593, which was collected from the South China Sea with the depth of $2918 \mathrm{~m}$. The structure of $\mathbf{1 1 7}$ was elucidated by 1D and 2D NMR spectral analysis while the absolute configuration of its stereogenic carbon was established by a comparison of the calculated and experimental ECD spectra [44]. Indolepyrazine B (118) (Figure 13) is a pyrazine-containing simple indole, obtained from an extract of a marine-derived Acinetobacter sp. ZZ1275, which was isolated from a mud sample collected from the coastal area of Karachi, Sindh, Pakistan [45].

\section{Bis-/Tris-Indoles}

A culture extract of Streptomyces sp. SCSIO 11791, isolated from a sediment sample collected from the South China Sea at a depth of $1765 \mathrm{~m}$ yielded two chlorinated bisindole alkaloids, dienomycin (119) and 6-methoxy- $7^{\prime}, 7^{\prime \prime}$-dichlorochromopyrrolic acid (120) (Figure 13). Compound 119 contains two indole moieties linked together through $1 H_{-}$ pyrrole-2,5-dione, while the two indole moieties in 120 are linked through dimethyl 2,5dihydro-1H-pyrrole-2,5-dicarboxylate. The structures of both compounds were elucidated by analysis of HRMS and 1D and 2D NMR spectra [46].<smiles>CC(=O)NCC[C@]1(O)C(=O)Nc2ccccc21</smiles>

117<smiles>CC(=O)C1NC(C(=O)O)C(c2c[nH]c3c(Cl)cccc23)=C1c1c[nH]c2c(Cl)cccc12</smiles>

120<smiles>Cc1cncc(Cc2c[nH]c3ccccc23)n1</smiles><smiles>O=C1NC(=O)C(c2c[nH]c3cc(Cl)c(Cl)cc23)=C1c1c[nH]c2ccc(Cl)cc12</smiles>

119<smiles>[R11]CCCCCCCC1(O)C(=O)Nc2ccccc21</smiles><smiles>c1ccc2c(CC[n+]3cc(-c4c[nH]c5ccccc45)cc(-c4c[nH]c5ccccc45)c3)c[nH]c2c1</smiles>

122

Figure 13. Structures of 117-122. 
Besides the simple indole 118, the culture of a marine-derived Acinetobacter sp. ZZ1275 also furnished a bis-indole alkaloid indolepyrazine A (121) (Figure 13) comprising one indole and one oxindole ring system linked by a 2, 2-dimethylpyrazine unit. The structure of 121 was elucidated by HRMS and 1D and 2D NMR spectral analysis. The configuration of the stereogenic carbon on the oxindole moiety was established through a comparison of the calculated and experimental ECD spectra [45].

Tricepyridinium (122) (Figure 13), a novel pyridinium with three indole moieties, was isolated from the culture extracts of the Escherichia coli transfected by metagenomic DNA prepared from the marine sponge Discoderma calyx collected from Shikine-jima Island in Japan. The structure of $\mathbf{1 2 2}$ was elucidated by a combination of HRMS with 1D and 2D NMR spectral analysis [47].

\subsection{Marine Invertebrates}

\subsubsection{Marine Sponges}

Marine sponges are also a source of structurally diverse indoles. However, only simple indoles and bis-/tris-indoles were reported from marine sponges in this period.

\section{Simple Indole Alkaloids}

Simple indole alkaloids consisting of an indole nucleus linked to a $N$-substituted- $\gamma$ lactams, named psammocindoles A-C (123-125) (Figure 14), were isolated from a marine sponge Psammocinia vermis (order Dictyoceratida, family Irciniidae) collected from Chujado, Korea. The structures of 123-125 were elucidated based on a combination of a highresolution fast atom bombardment mass spectrometry (HRFABMS) and 1D and 2D spectral analysis. In the case of 123, the absolute configuration of the stereogenic carbon was determined by a comparison of its optical rotation with that of a synthetic version [48].

The 5-azaindole derivatives, guitarrins A-E (126-130) and an aluminum complex compound, aluminumguitarrin A (126a), (Figure 14), were isolated from the marine sponge Guitarra fimbriata. Compounds 126-129 and 126a were isolated from the sample of G. fimbriata, collected by dredging near Chirpoy Island in the Pacific Ocean, while 130 was isolated from a sample of the same sponge but collected near Urup Island, Sea of Okhotsk. The structures of all the isolated compounds were elucidated by HRMS and 1D and 2D NMR spectral analysis. In the case of 126 and 126a, their structures were confirmed by a single-crystal X-ray diffraction analysis [49].

Seven pairs of oxygenated aplysinopsin-type enantiomers, (+)- and (-)-oxoaplysinopsins A-G (131-137) (Figures 14 and 15) were isolated from a marine sponge Fascaplysinopsis reticulata, which was collected from Xisha Island in the South China Sea. The enantiomers were separated by a chiral HPLC equipped with a chiral analytical column (CHIRALPAK IC column). The planar structures of all compounds were determined by extensive analysis of NMR spectroscopic and HRMS data while the absolute configurations of the stereogenic carbons in the compounds were established by a comparison of their calculated and experimental ECD spectra [50].

An alkyl-guarnidine-substituted diketopiperazine-containing bromooxindole, geobarrettin A (138), an alkylguarnidine-substituted diketopiperazine-containing bromoindole, geobarrettin B (139), and geobarrettin C (140) (Figure 15), a trimethyloxoammoniumcontaining bromoindole, were isolated from a sub-Arctic sponge Geodia barretti collected from the west of Iceland. The structures of 138-140 were elucidated by interpretation of HRMS and 1D and 2D NMR spectral data. The configuration of C-3 of the oxindole moiety in 138 was determined by a comparison of the ECD spectra of the hydrolysis product of 138 and of $(R)$-3-proplyldioxindole, while the absolute configuration of C-12 of the diketopiperazine ring was determined by Marfey's method [51]. 


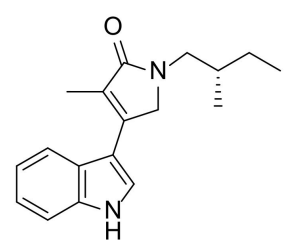

123

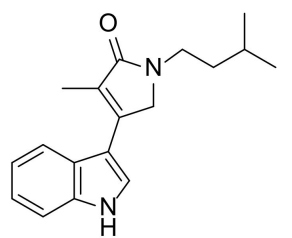

124

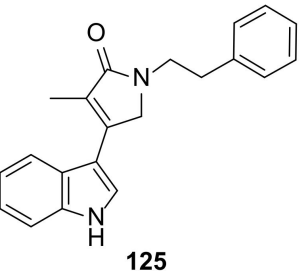

125<smiles>O=C([O-])c1cc[nH]c1-c1ccccc1</smiles>

126

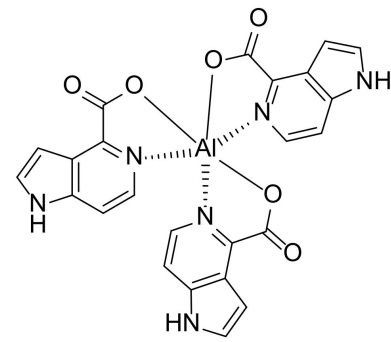<smiles>OCc1cc[nH]c1-c1ccccc1</smiles>

127<smiles>Cn1cc2cccc-2c(C(=O)[O-])c1CO</smiles>

128<smiles>C[C@H]1NC(CO)c2cc[nH]c2C1O</smiles>

126a<smiles>O=C([O-])CCCC1=NCC(O)c2[nH]ccc21</smiles><smiles>CN1C(=O)C(=Cc2c(O)[nH]c3ccccc23)C(=O)N1C</smiles><smiles></smiles><smiles></smiles><smiles>CN1C(=O)C(C2C(=O)NC(=O)N2C)C(O)c2ccccc21</smiles>

Figure 14. Structures of 123-132.<smiles></smiles>

$133 a$<smiles>COC(=O)C1(C(=O)O)C(=O)N(C)C(=O)N1C</smiles>

136a, $\mathrm{R}=\mathrm{H}$ $137 a, R=M e$<smiles>CN1C(=O)[C@H](O)[C@H](Cc2c(O)c(=O)[nH]c3ccccc23)N1C</smiles>

133b

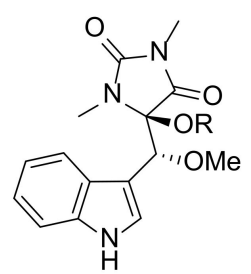

134a, $\mathrm{R}=\mathrm{H}$ 135a, $R=M e$

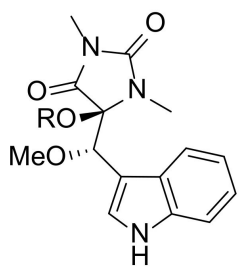

134b, $\mathrm{R}=\mathrm{H}$ 135b, $R=M e$

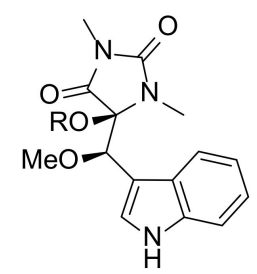

136b, $\mathrm{R}=\mathrm{H}$

137b, $\mathrm{R}=\mathrm{Me}$<smiles>N=C(N)NCCCC1NC(=O)C(=CC2(O)C(=O)Nc3cc(Br)ccc32)C(=O)N1</smiles>

138<smiles>NC(N)NCC/C=c1/[nH]c(=O)/c(=C/c2c[nH]c3cc(Br)ccc23)[nH]c1=O</smiles><smiles>CN(C)CC(=O)c1c[nH]c2cc(Br)ccc12</smiles>

Figure 15. Structures of 133-140. 
Bis-/Tris-Indole Alkaloids

Dragmacidin G (141) (Figure 16), a bis-bromoindole linked by a pyrazine ring with a $N$-(2-mercaptoethyl)-guanidine side chain, was isolated from the marine sponge of an unidentified species of Spongosorites (Family Halichondriidae) collected from Long Island, Bahamas by the Johnson-Sea-Link I manned submersible at a depth of $630 \mathrm{~m}$. The structure of the compound was elucidated by extensive analysis of NMR spectra and HRMS [52]. Compound 141 was also isolated, together with dragmacidin H (142) (Figure 16), from a marine sponge Lipastrotethya sp., which was collected by dredging at Kurose, north of Hachijo Island, Japan [53]. Compound 142 differs from 141 in that only one indole moiety is brominated and the side chain of the pyrazine ring is $\mathrm{N}$-(2-mercaptomethyl)-guanidine instead of $\mathrm{N}$-(2-mercaptoethyl)-guanidine.

Dihydrospongotine C (143) (Figure 16), a member of bis-indole alkaloids comprising two bromoindole moieties linked together by 4,5-dihydro- $1 H$-imidazol-2ylmethanol, was isolated from a deep-sea sponge Topsentia sp. collected in Palau at the depth of $140 \mathrm{~m}$. The structure of the compound was established by extensive analysis of 1D and 2D spectra and HRMS data. The absolute configurations of the stereogenic carbons were established by a comparison of the calculated and experimental ECD spectra as 4S, 6S [54].

Splendamide (144) (Figure 16), a bis-bromoindole-3 carboxamide, was isolated from a marine sponge Jaspis splendens, which was collected by scuba diving $(-23 \mathrm{~m})$ at Mid Reef, Great Barrier Reef, North Queensland, Australia. Indole-3-carboximidamides are rarely encountered in nature and only a few examples have been reported [55].

Cis/trans isomers of bis-indoles connected through an $\alpha$-ketovinylamide moiety, named (Z)-coscinamide D (145) and (E)-coscinamide D (146) (Figure 16), were isolated together with four bis-indoles linked through a diketoamide moiety, lamellomorphamides A-D (147-150) (Figure 16), from a marine sponge Lamellomorpha strongylata, which was collected from the Western Continental Slope (Station J954), Northland, New Zealand, at a depth of $200 \mathrm{~m}$. Although 147-150 were new natural products, they had been previously reported as intermediates in the synthesis of $6^{\prime}, 6^{\prime \prime}$-didebromo-cis-3,4-dihydrohamacanthin B, 6' debromo-cis-3,4-dihydrohamacanthin B, and hamacanthin analogues [56].

Calcicamides A (151) and B (152) (Figure 16), two bis-indole alkaloids comprising one indole and one 6-bromoindole connected through an aminoalkyl $\alpha$-ketoamide moiety, were isolated from a marine sponge Spongosorites calcicole collected at Rathlin Island (Co. Antrim), Northern Ireland, at a $18 \mathrm{~m}$ depth. Compounds 151 and $\mathbf{1 5 2}$ are constitutional isomers as they have the same molecular formula. 1D and 2D-NMR spectral analysis revealed that both compounds have an indole portion linked to the $\alpha$-ketoamide moiety that is connected to C-8 and C-9 of 6-bromotryptamine in 151 and 152, respectively. The absolute configuration of the stereogenic carbon (C-8) of both compounds was established as $S$ through a comparison of the calculated and experimental ECD spectra. The structures of 151 and 152 were hypothesized as intermediates in the biosynthesis of a cyclic structure that linked to both indole moieties such as spongotine and toptensin as well as the hamacanthin B derivative [57].

Dragmacidins I (153) and J (154) (Figure 17), bis-indole alkaloids featuring one indole and one 6-bromoindole linked to C-2 and C-5 of a piperazine ring, were isolated from a marine sponge Dragmacidon sp., which was collected from Kashani Island in Tanzania. The absolute configurations of the stereogenic carbons in $\mathbf{1 5 3}$ and $\mathbf{1 5 4}$ were proposed to be $2 R, 5 S$ on the basis of their measured optical rotation values, which were very close to those reported for dragmacidin A, prepared by enantioselective total synthesis [58].

Spongosoritins A-D (155-158) (Figure 17), bis-indole alkaloids comprising two indole moieties linked through a 2-keto-2-methoxy-1-imidazole-5-one core, along with spongocarbamides A (159) and B (160) (Figure 17), another two bis-indoles whose two indole moieties were connected through a linear type keto urea, were isolated from a marine sponge Spongosorites sp. collected at the depth of 25-30 m offshore Seogwipo, Jeju Island, Korea. The structures of 155-160 were elucidated by a combination of HRMS and 1D and 2D NMR spectral analysis. The absolute configuration of the stereogenic carbon in the imidazolone 
ring of 155-158 was established by comparison of the calculated and experimental ECD spectra [59].<smiles>N=C(N)NCCSc1nc(-c2c[nH]c3cc(Br)ccc23)cnc1-c1c[nH]c2cc(Br)ccc12</smiles><smiles>N=C(N)CNCSc1nc(-c2c[nH]c3ccccc23)cnc1-c1c[nH]c2cc(Br)ccc12</smiles>

42<smiles>CCN1CC(c2c[nH]c3cc(Br)ccc23)NC1C(O)c1c[nH]c2cc(Br)ccc12</smiles>

143<smiles>[R2]c1ccc2c(C(=O)CNC(=O)C(=O)c3c[nH]c4cc([R])ccc34)c[nH]c2c1</smiles>

150, $R_{1}=R_{2}=B r$<smiles>NCCc1c[nH]c2cc(Br)ccc12</smiles><smiles>NC(CNC(=O)C(=O)c1c[nH]c2ccccc12)c1c[nH]c2cc(Br)ccc12</smiles>

Figure 16. Structures of 141-152.

Tulongicin A (161) (Figure 17) is a tris-indole alkaloid featuring an imidazole ring connected to three 6-bromoindole units. One of the 6-bromoindole is directly linked to C-4 of the indole core while another two 6-bromoindole units formed a bis(indolyl) methane moiety and linked to C-2 of the imidazole ring. Compound 161 was isolated together with 141 from a deep-water marine sponge Topsentia sp. [54].

5-Bromotrisindoline (162) and 6-bromotrisindoline (163) (Figure 17) are tris-indole alkaloids comprising two indoles and one bromooxindole linked together through C-3 of each indole unit. The difference between 162 and 163 is that the bromine atom is on C-5 of the oxindole ring in 162, but on C-6 in 163. Although 162 and 163 were first isolated as new natural products from a marine sponge Callyspongia siphonella collected from Hurghada, Egypt, along the Red Sea Coast, they have already been reported as synthetic intermediates [60].

A bis-indole alkaloid, myrindole A (164) (Figure 17), was isolated from a marine sponge Myrmekioderma sp. collected in Sagosone, Japan. Compound 164 features a tetrahydroquinoxaline ring system fused with imidazolidin-2-imine as a central core, having the cyclohexane ring fused with 6-bromoindole while C-2 of the pyrazine ring is linked to an indole moiety. Besides the usual 1D and 2D NMR spectral analysis, ${ }^{1} \mathrm{H}_{-}{ }^{15} \mathrm{~N}$ HMBC and 1,n-ADEQUATE correlations were used to unravel this complex structure. The absolute 
configurations of C-5 and C-6 in 164 were determined as $5 S, 6 R$ by comparison of the calculated and experimental ECD spectra [61].<smiles>[R]N1C[C@H](c2c[nH]c3ccccc23)CN(C)C1c1c[nH]c2ccccc12</smiles>

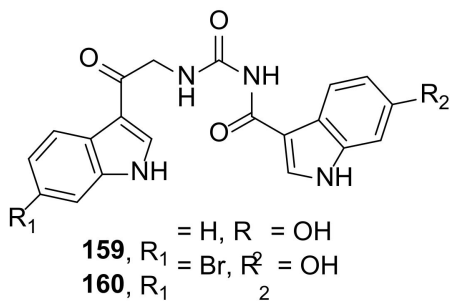<smiles>O=C1Nc2ccc(Br)cc2C1(c1c[nH]c2ccccc12)c1c[nH]c2ccccc12</smiles>

162<smiles>O=C1Nc2cc(Br)ccc2C1(c1c[nH]c2ccccc12)c1c[nH]c2ccccc12</smiles>

163<smiles></smiles><smiles>Brc1ccc2c(C(C3=NC[C@H](c4c[nH]c5cc(Br)ccc45)N3)c3c[nH]c4cc(Br)ccc34)c[nH]c2c1</smiles>

161<smiles>C[C@]12NC(=N)N[C@H]1c1nc(-c3c[nH]c4ccccc34)cnc1-c1c2[nH]c2cc(Br)ccc12</smiles>

164

Figure 17. Structures of 153-164.

\subsubsection{Bryozoans}

Bryozoans are another rich source of indole alkaloids. Simple, prenylayed, and annelated indoles have been reported from bryozoans.

\section{Simple Indole Alkaloids}

During a high-throughput screening of an Australian marine invertebrate extract library against Plasmodium falciparum, Kleks et al. [62] isolated 2,5-dibromo-1-methyl-1Hindole-3-carbaldehyde (165) (Figure 18) from samples of a bryozoan Amathia lamourouxi, collected from the rock pools of Woolgoolga and as storm debris from Korora Beach, Coffs Harbour, New South Wales, Australia.

Prenylated Indoles

The organic extract of a marine bryozoan Flustra foliacea, collected near the southwest coast of Iceland at $13 \mathrm{~m}$ depth, furnished 13 prenylated indole alkaloids, viz. flustramines Q-W (166-172) and flustraminols C-H (173-178) (Figure 18). Although the structures of 166 and 168 apparently do not contain the indole ring system, they were derived from the degradation and rearrangement of the indole nucleus. Compound 167 shows interesting features with $N, N$-dimethylaminoethyl and thiomorpholine 1,1-dioxide ring substituents, while $\mathbf{1 6 9}$ is a bis-indole with one of the indole rings fused with a prenyl-derived bicyclic system. Compounds 175-177 are diprenylated pyrrolidine-fused indoles. The structures of the compounds were elucidated by extensive analysis of 1D and 2D NMR spectra and HRMS data. In the case of 167, the absolute configurations of the stereogenic carbons were determined by a comparison of the calculated and experimental ECD spectra of its bis-trifluoroacetate double salt. The absolute configurations of the stereogenic carbons in $171,172,174,175-178$ were established based on a comparison of the CEs of their ECD 
spectra with those of the compounds containing related chromophores and whose absolute structures have been established. Only relative configurations of the stereogenic carbons of $\mathbf{1 7 3}$ and $\mathbf{1 7 8}$ were determined by NOESY correlations and by observation of the ${ }^{1} \mathrm{H}$ chemical shift values, respectively [63].

Annelated Indole Alkaloids

Securamines H-J (179-181) (Figure 18), hexacyclic annelated indole alkaloids featuring an imidazolone-containing bromoindole fused with pyrrolidinone moiety, were isolated from the Arctic bryozoan Securiflustra securifrons, collected by an Agassiz trawl at $73 \mathrm{~m}$ depth from west Spitzbergen. The structures of the compounds were established by extensive analysis of 1D and 2D NMR spectra and HRMS data, however, the absolute configurations of their stereogenic carbons were not determined [64].<smiles>Cn1c(Br)c(C=O)c2cc(Br)ccc21</smiles>

165<smiles>CC(C)C(=O)c1c(CCN(C)C)c2ccc(Br)cc2[nH]c1=O</smiles>

166<smiles>CN(C)CCc1c([C@@H]2NCCS(=O)(=O)[C@@H]2NCC(C)(C)O)[nH]c2cc(Br)ccc12</smiles>

167<smiles>C=CC(C)(C)C(=O)Nc1cc(Br)ccc1C(=O)O</smiles>

168

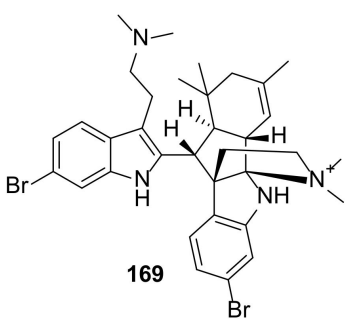<smiles>C=CC(C)(C)c1[nH]c2cc(Br)ccc2c1CC[N+]1(C)CCOC1</smiles><smiles>C=CC(C)(C)C1(C/C=C\NC)C(=O)Nc2cc(Br)ccc21</smiles><smiles>CNCCC1(O)C(=O)N(CC=C(C)C)c2cc(Br)ccc21</smiles><smiles>[R]C(C(O)C(C)(C)O)N1c2cc(Br)ccc2[C@@]2(CC=C(C)C)CCN(C)[C@@]12C</smiles>

$173, \mathrm{R}=\mathrm{H}$ 174, $\mathrm{R}=\mathrm{OH}$

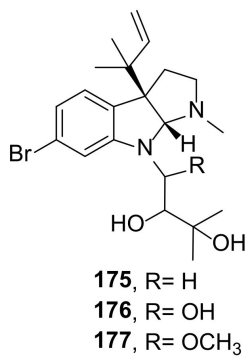

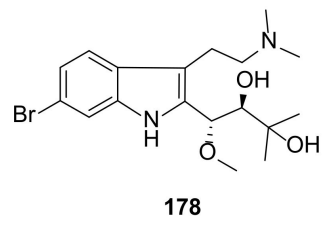

176, $\mathrm{R}=\mathrm{OH}$

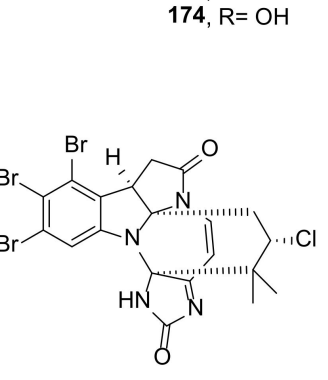

179

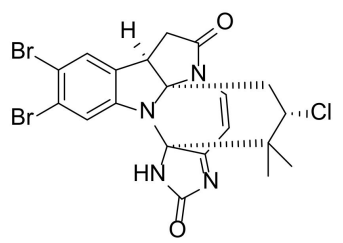

180

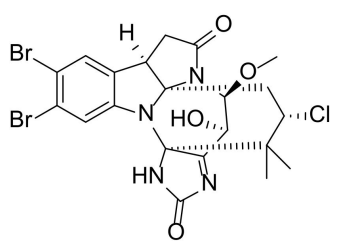

181

Figure 18. Structures of 165-181.

\subsection{Marine Plants}

Marine plants seem to not be very good producers of indole alkaloids. Only one marine alga and one mangrove plant have been reported as sources of indole alkaloids during this period.

\subsubsection{Algae}

Four brominated indoles (182-185) (Figure 19) were isolated from the organic extract of the marine alga Laurencia similis collected in the South China Sea. Compound $\mathbf{1 8 2}$ is a simple 
dibromoindole with a benzyl group on C-3 of the indole core while $\mathbf{1 8 3}$ is an oxindole with a 2-propylidene on C-3. On the other hand, 184 is an annelated bromoindole while 185 features a carbamate-containing benzoic acid derivative resulting from the oxidative ring opening of a pyrrole ring of the indole nucleus [65].

\subsubsection{Mangrove Trees}

An annelated indole, acanthiline A (186) (Figure 19), featuring a pyrido[1,2-a]indole skeleton, was isolated from a mangrove tree Acanthus ilicifolius Linn, collected at the Zhanjiang Mangrove National Nature Reserve, Guangdong Province, China [66].<smiles>Oc1ccc(Cc2c(Br)[nH]c3cc(Br)c(Br)cc23)cc1Br</smiles>

182<smiles>CC(C)=C1C(=O)N(O)c2cc(Br)c(Br)cc21</smiles>

183<smiles>Cc1cc(C)c2[nH]c3cc(Br)c(Br)cc3c2c1</smiles>

184<smiles>COC(=O)Nc1cc(Br)c(Br)cc1C(=O)OC</smiles><smiles>COC1=CC(=O)c2c(OC)c3ccccc3n2C1=O</smiles>

Figure 19. Structures of 182-186.

\section{Biological and Pharmacological Activities of Indole Alkaloids}

\subsection{Antimicrobial Activity}

Although the prenylated indoles, 2-(2-methyl-3-en-2-yl)-1H-indole-3-carbaldehyde (9) and 2-(2,2-dimethylcyclopropyl)-1H-indole-3-carbaldehyde (10) (Figure 4) did not show antibacterial activity against either Gram-negative (Escherichia coli ATTC 25922 and Pseudomonas aeruginosa ATTC 27853) or methicillin-resistant Streptococcus aureus (MRSA) and vancomycin-resistant enterococci (VRE), both compounds showed inhibition of biofilm production in S. aureus ATCC 25923, while only 10 significantly reduced biofilm production by E. coli ATCC 25922. Moreover, 9 and 10 induced a weak increase in the halo of a partial inhibition of vancomycin in VRE Enterococcus faecalis B3/101 when compared to vancomycin alone, whereas 9 showed a modest synergistic effect with cefotaxime in the impregnated disks against extended spectrum $\beta$-lactamase (ESBL) E. coli strain SA/2 [14].

The prenylated indoles, asperthins A-F (41-46) (Figure 6), were evaluated for their activities against agricultural pathogenic bacteria and fungi. Asperthin A (41) exhibited both antibacterial and antifungal activities with MIC values of 50, 12.5, and $100 \mu \mathrm{g} / \mathrm{mL}$ against the bacteria Xanthomonas oryzae pv. oryzae and X. oryzae pv. oryzicola, and the fungus Rhizoctonia solani, respectively. Moreover, $\mathbf{4 1}$ also showed moderate antibacterial activity against four fish pathogens, viz. Edwardsiella tarda, Vibrio anguillarum, V. parahaemolyticus, and Aeromonas hydrophilia, with MIC values of 16, 8, 16, and $32 \mu \mathrm{g} / \mathrm{mL}$, respectively. Except for X. oryzae pv. oryzicola, 41 showed higher MIC values against all the tested bacteria (MIC of chloromycetin, a positive control, against X. oryzae pv. Oryzae, X. oryzae pv. Oryzicola, E. tarda, V. anguillarum, V. parahaemolyticus, and A. hydrophilia $=12.5,12.5$, 2, 0.5, 2 and $2 \mu \mathrm{g} / \mathrm{mL}$, respectively). On the other hand, asperthin E (45) only showed weak antifungal activity against $R$. solani with a MIC value of $25 \mu \mathrm{g} / \mathrm{mL}$ (MIC of a positive control, ketoconazole $=0.7825 \mu \mathrm{g} / \mathrm{mL})$ [22].

Penochalasins I (81), J (82) and K (83) (Figure 10) were evaluated for the in vitro antifungal activity against plant pathogenic fungi viz. Colletotrichum gloeosporioides, $R$. solani, Colletotrichum musae, and Penicillium italicum. Compound $\mathbf{8 1}$ was inactive against all the pathogenic 
fungi while 82 showed moderate activity against $C$. gloeosporioides $(\mathrm{MIC}=25.08 \mu \mathrm{M})$ and $R$. solani $(\mathrm{MIC}=50.17 \mu \mathrm{M})$ and 83 exhibited more potent activity against $C$. gloeosporioides $(\mathrm{MIC}=6.13 \mu \mathrm{M})$ and $R$. solani $(\mathrm{MIC}=12.26 \mu \mathrm{M})$, respectively. Both 82 and 83 showed MIC values lower than a positive control, carbendazim, against $C$. gloeosporioides and R. solani (MIC values of 65.38 and $32.69 \mu \mathrm{M}$, respectively [34,35].

The quinazoline-containing indoles, aspertoryadins F (91) and G (92) (Figure 11) were evaluated for their antibacterial activity against $S$. aureus, E. coli, Bacillus subtilis, and Streptococcus agalactiae as well as quorum sensing (QS) inhibitory activity against Chromobacterium violaceum CV026. Both compounds were found to be void of antibacterial activity but exhibited QS inhibitory activity against C. violaceum CV026 with MIC values of $32 \mu \mathrm{g} /$ well whereas the positive control, bromofuranone C30, exhibited a MIC value of $1 \mu \mathrm{g} /$ well [40].

Fumigatoside E (93) (Figure 11) showed antibacterial activity against Gram-negative bacteria Acinetoobacter baumannii ATCC 19606, A. baumannii ATCC 15122, and Klebsiella pneumoniae ATCC 14578, and a Gram-positive bacterium, S. aureus ATCC 16339 as well as two strains of fungi Fusarium oxysporum f. sp. cucumerinum and F. oxysporum f. sp. momordicae. Compound 93 exhibited moderate to strong activity, with MIC values of $6.25 \mu \mathrm{g} / \mathrm{mL}$ against A. baumannii ATCC 15122 and S. aureus ATCC 16339, and $12.5 \mu \mathrm{g} / \mathrm{mL}$ against A. baumannii ATCC 19606 and K. pneumoniae ATCC 14578. Interestingly, the MIC value of 93 against $A$. baumannii ATCC 15122 was half the MIC value of a positive control, streptomycin $(\mathrm{MIC}=12.5 \mu \mathrm{M})$ while fumigatoside $\mathrm{F}(88)$ only exhibited moderate antibacterial activity against $A$. baumannii ATCC 19606, with a MIC value of $6.25 \mu \mathrm{M}$ (streptomycin showed MIC value $=1.565 \mu \mathrm{M})$. In contrast, 93 exhibited weak activity against $F$. oxysporum $\mathrm{f}$. sp. cucumerinum $(\mathrm{MIC}=25 \mu \mathrm{M})$ but strong activity against F. oxysporum $\mathrm{f}$. sp. momordicae $(\mathrm{MIC}=1.565 \mu \mathrm{M})$ when compared to nystatin, a positive control, whose MIC value was $12.5 \mu \mathrm{M}[41]$.

The bis-indole alkaloids, dienomycin (119) and 6-methoxy- $7^{\prime}, 7^{\prime \prime}$-dichorochromopyrrolic acid (120) (Figure 13), were evaluated for antibacterial activity by a disk diffusion method against Gram-positive bacteria including Micrococcus luteus ML01, S. aureus ATCC 29213, and a panel of MRSA isolated from human patients (MRSA 991, MRSA 1862, MRSA 669 A, and MRSA A2) and pig (MRSA GDQ6P012P and MRSA GDE4P037P) as well as Gramnegative bacteria including A. baumannii ATCC 19606, Vibrio coralliilyticus ATCC BAA-450, and $V$. alginolyticus XSBZ14, however, 119 and 120 showed growth inhibition of Grampositive bacteria, but not Gram-negative bacteria, at $10 \mu \mathrm{g}$ per filter paper. Determination of MIC by a broth microdilution method revealed that 119 was many folds more active than 120 toward M. luteus ML01, S. aureus ATCC 29213, and all the MRSA strains, especially M. luteus ML01 (MIC = $0.5 \mu \mathrm{g} / \mathrm{mL})$ and S. aureus ATCC $29213(\mathrm{MIC}=1 \mu \mathrm{g} / \mathrm{mL})$. Moreover, 119 displayed lower MIC value than kanamycin but higher MIC value than vancomycin, which were used as positive controls against these microorganisms. Structure-activity relationship (SAR) study revealed that the presence of a chlorine atom on C-6" of the indole moiety played a crucial role in the antibacterial activity of this series of compounds [46].

Pyrazine-containing indolepyrazines A (121) and B (118) (Figure 13) showed potent antimicrobial activities against methicillin-resistant $S$. aureus (MRSA), E. coli, and Candida albicans with MIC values of $12 \mu \mathrm{g} / \mathrm{mL}, 8-10 \mu \mathrm{g} / \mathrm{mL}$, and 12-14 $\mu \mathrm{g} / \mathrm{mL}$, respectively. However, the MIC values of both $\mathbf{1 1 8}$ and $\mathbf{1 2 1}$ were several folds higher than the positive controls, gentamicin for antibacterial, and amphotericin B for antifungal activities. Interestingly, the absence of 1-hydroxy-1,3-dihydro-2H-indol-2-one moiety in $\mathbf{1 1 8} \mathrm{did}$ not affect the potency of antibacterial and antifungal activities on the tested strains [45].

A bromide salt of a synthetic version of tricepyridinium (122) (Figure 13) was found to display a significant antibacterial activity against Bacillus cereus with a MIC value of $0.78 \mu \mathrm{g} / \mathrm{mL}$ and methicillin-sensitive $S$. aureus (MSSA) with a MIC value of $1.56 \mu \mathrm{g} / \mathrm{mL}$ as well as a moderate antifungal activity against C. albicans with a MIC value of $12.5 \mu \mathrm{g} / \mathrm{mL}$. However, the compound did not show any activity against E. coli at $100 \mu \mathrm{g} / \mathrm{mL}$. Structureactivity relationship study with a synthetic version and two indole moieties revealed that 
the three indole moieties of $\mathbf{1 2 2}$ and the charged pyridinium were mainly responsible for a strong cytotoxicity toward Gram-positive bacteria and fungi. Moreover, it was found that the indole group at the 3- or 5-position was more important than an indole group at the $8^{\prime \prime}$-position [47].

A pyrazino bis-indole dragmacidin G (141) (Figure 16) was found to exhibit a potent antibacterial activity against $S$. aureus and MRSA with MIC values of $0.62 \mu \mathrm{g} / \mathrm{mL}(1 \mu \mathrm{M})$ for both strains. Compound $\mathbf{1 4 1}$ also displayed an anti-mycobacterial activity in the assay that used Mycobacterium tuberculosis CDC1551 carrying the pMV306hsp-LuxG13 integrative plasmid, which provides constitutive expression of the luxCDABE operon [52].

The bis-indoles, spongosoritins A-D (155-158) and spongocarbamides A (159) and B (160) (Figure 17) were assayed for their antibacterial activity against Gram-positive (S. aureus, E. faecalis, E. faecium) and Gram-negative (K. pneumoniae, Salmonella enterica, E. coli) bacteria. Most of the compounds showed weak activity against the tested bacterial strains except for 156-158 and 159, which showed moderate activity against S. aureus with MIC values of $64,32,16$, and $64 \mu \mathrm{g} / \mathrm{mL}$ (a positive control, ampicillin showed MIC $=0.13 \mu \mathrm{g} / \mathrm{mL}$ ) whereas 157 and 158 showed moderate activity against $S$. enterica with MIC values of $64 \mu \mathrm{g} / \mathrm{mL}$ (ampicillin showed MIC $=0.25 \mu \mathrm{g} / \mathrm{mL}$ ). Since sortase A (Srt A), a bacterial cell membrane transpeptidase enzyme that anchors crucial virulence factors to the cell wall surface of Gram-positive bacteria, plays crucial roles in the pathogenesis of Gram-positive but is not necessary for bacterial growth and viability, 155-159 were also assayed for their Srt A inhibitory activity using a recombinant SrtA derived from S. aureus ATCC6538p. Interestingly, only 156, 157, 159, and 160 showed inhibition of Srt A with $\mathrm{IC}_{50}$ values of $62.7,43.9,79.4$, and $52.4 \mu \mathrm{M}$ (the positive controls, triphasiol and berberine chloride, showed $\mathrm{IC}_{50}$ values of 37.9 and $87.4 \mu \mathrm{M}$, respectively) [59].

The bis-indole dihydrospongotine C (143) (Figure 16) and the tris-indole tulongicin A (161) (Figure 17) were evaluated for their antibacterial activity against Gram-positive S. aureus ATCC 29213 and Gram-negative E. coli ATCC 25922. Interestingly, both compounds showed strong antibacterial activity against $S$. aureus with MIC values of 3.7 and $1.2 \mu \mathrm{g} / \mathrm{mL}$, respectively (MIC of a positive control, oxacillin, was $0.25 \mu \mathrm{g} / \mathrm{mL}$ ). On the other hand, 143 showed weak activity $((\mathrm{MIC}=100 \mu \mathrm{g} / \mathrm{mL})$ while 161 was inactive (MIC $>100 \mu \mathrm{g} / \mathrm{mL})$ against $E$. coli at the highest concentration tested $(100 \mu \mathrm{g} / \mathrm{mL})$ [54].

5-Bromotrisindoline (162) and 6-bromotrisindoline (163) (Figure 17) exhibited moderate to strong antibacterial activity against Gram-positive bacteria, S. aureus and B. subtilis, with MIC values of 8 and $4 \mu \mathrm{g} / \mathrm{mL}$, and 16 and $4 \mu \mathrm{g} / \mathrm{mL}$, respectively. In contrast, both compounds did not display any antibacterial activity against Gram-negative bacteria, E. coli and $P$. aeruginosa (MIC $\geq 256 \mu \mathrm{g} / \mathrm{mL}$ ). Curiously, the previously described tris-indoline, a non-brominated analog of 162 and 163, displayed antibacterial activity against E. coli, P. aeruginosa, and B. subtilis [67], implying that introducing a bromine atom into the oxindole moiety of tris-indoline decreases the antibacterial spectrum of these molecules. Interestingly, although 162 and 163 did not exhibit antibacterial activity against $P$. aeruginosa, both compounds, at $\frac{1}{2}$ MIC concentration, were able to inhibit biofilm formation in P. aeruginosa PA01 with $49.32 \%$ and $41.76 \%$ inhibition, respectively (a positive control, azithromycin, showed $52.62 \%$ inhibition). Therefore, 162 and 163 could be considered as potential antibiotic adjuvants [60].

The bis-indole alkaloid myrindole A (164) (Figure 17) was found to inhibit the growth of E. coli and B. subtilis with MIC values of 37.5 and $18.5 \mu \mathrm{M}$, respectively [61]. The structure of 164 was quite similar to that of dragmacidin E, except for the substitution pattern of the pyrazine ring [67].

The brominated indoles 182-185 (Figure 19) from marine alga Laurencia similis were evaluated for antibacterial activity against three Gram-positive bacteria (S. aureus, B. subtilis, B. thuringensis) and four Gram-negative (Pseudomonas lachrymans, Agrobacterium tumefaciens, Xanthomonas vesicatoria, and Ralstonia solanacearum) bacteria. While 182 exhibited potent inhibitory activity against both Gram-positive and Gram-negative bacterial strains tested with MIC values ranging from 2-8 $\mathrm{g} / \mathrm{mL}, 183$ showed weak activity against both Gram- 
positive and Gram-negative with MIC values ranging from 12.5-50 $\mu \mathrm{g} / \mathrm{mL}$. Compounds 184 and 185 did not have any effect on the bacterial strains tested (MIC >250 $\mu \mathrm{g} / \mathrm{mL}$ ), except for 184, which showed weak activity (MIC $=50 \mu \mathrm{g} / \mathrm{mL}$ against X. vesicatoria [65].

\subsection{Antiviral Activity}

Fusariumindole C (1), ( \pm )-isoalternatine A (2) (Figure 3), fusaindoterpenes A (48) and B (49) (Figure 6), and fusariumindoles A (75) and B (74) (Figure 10), were evaluated for their antiviral activity against the Zika virus (ZIKV) by a plaque assay on A549 (human lung carcinoma) cell cultures. Compounds 48, 49, 74, and 75 exhibited anti-ZIKV activity with $\mathrm{EC}_{50}$ values of $12,7.5,50$, and $48 \mu \mathrm{M}$, respectively. Interestingly, 49 was two-fold more potent against ZIKV than the adenosine analog NITD008, which is a potent inhibitor of ZIKV (NITD008, a positive control, showed an EC $_{50}$ value of $15 \mu \mathrm{M}$ ). Preliminary structureactivity relationship study of these compounds, in comparison with the related compounds previously reported, revealed that the intact pyrrole ring of the indole moiety fused with the cyclopentane ring is required for the activity since introducing an oxygen atom to the pyrrole ring caused a loss of activity in 48 when compared to 49 [7].

The fungal indoleterpenoids, ascandanines B-D (64-66) (Figure 9), were evaluated for their antiviral effects against the influenza A virus (H1N1) by the cytopathic effect (CPE) inhibition assay. However, only 65 displayed an anti-influenza A effect with $\mathrm{IC}_{50}=26 \mu \mathrm{M}$, which is more potent than the positive control, ribavirin $\left(\mathrm{IC}_{50}=31 \mu \mathrm{M}\right)$ while 64 and 66 were inactive $\left(\mathrm{IC}_{50}>150 \mu \mathrm{M}\right)$ [27].

The fungal diketopiperazine indole alkaloid, raistrickindole A (90) (Figure 11), was assayed for its in vitro inhibitory activity against the hepatitis $C$ virus (HCV) life cycles. Compound 90 showed an anti-HCV activity with an $\mathrm{EC}_{50}$ value of $5.7 \mu \mathrm{M}$, which is many folds higher than the $\mathrm{EC}_{50}$ value $(0.05 \mu \mathrm{M})$ of the positive control, VX-950 [39]. Scequinadolines A (106), D (109), E (110) (Figure 12), G (7) (Figure 3), and scedapins A (112), C (114) (Figure 12), and E (94) (Figure 11) were also tested for activity against $\mathrm{HCV}$. However, only 106 and $\mathbf{1 1 4}$ displayed significant anti-HCV activity against the J8CC recombinant with $\mathrm{EC}_{50}$ values of 128.60 and $110.35 \mu \mathrm{M}$, respectively [12].

Dihydrospongotine C (143) (Figure 16) and tulongicin A (161) (Figure 17) were evaluated for their anti-HIV activity in HIV infectivity assays against the CCR5-tropic primary isolate YU2 and the CXCR4-tropic strain HxB2. Compounds 143 and 161 displayed $\mathrm{IC}_{50}$ values of 3.5 and $3.9 \mu \mathrm{M}$ against YU2 and 4.5 and $2.5 \mu \mathrm{M}$ against HxB2, respectively [54].

\subsection{Anticancer Activity}

17-O-Ethylnotoamide M (16), 17-hydroxynotoamide D (23) and 10-O-ethylnotoamide R (33) (Figure 4) were evaluated for their effects on the viability of human non-malignant and prostate cancer cells as well as on the colony formation of human prostate cancer cells 22Rv1, which are known to be resistant to hormone therapy including the novel second generation drugs abiraterone and enzalutamide due to the presence of androgen receptor splice variant AR-V7. Compound $\mathbf{1 6}$ did not display cytotoxicity to non-malignant human lung (MRC-9) and human kidney (HEK 293 T) cell lines as well as malignant prostate cancer (22Rv1, PC-3, and LNCaP) cell lines at concentrations up to $100 \mu \mathrm{M}$ after $48 \mathrm{~h}$ of treatment. Moreover, 16 inhibited the colony formation of 22Rv1 cells at a concentration of $100 \mu \mathrm{M}$ and significantly decreased colony formation at a concentration of $10 \mu \mathrm{M}$ by $25 \%$ [17].

Ascandinines A-D (63-66) (Figure 9) were also evaluated for their cytotoxicity against MGC-803 (human gastric carcinoma), HCT-116 (human colorectal), SH-SY5Y (human neuroblastoma), Hela, and HL-60 (promyelocytic leukemia) cell lines. However, only 66 was active against the HL-60 cells with an $\mathrm{IC}_{50}$ value of $7.8 \mu \mathrm{M}$ (the $\mathrm{IC}_{50}$ value of a positive control, adriamycin, was $0.02 \mu \mathrm{M})$ [27].

Asperindoles A (67) and C (69) (Figure 9) were assayed for cell viability, cell cycle progression, and induction of apoptosis in human prostate cancer cell lines 22Rv1, PC-3, and LNCaP. Compound 67 exhibited cytotoxicity in all three cell lines, with $\mathrm{IC}_{50}$ values 
of $69.4,47.8$, and $4.86 \mu \mathrm{M}$, respectively (a positive control, docetaxel, showed $\mathrm{IC}_{50}$ values of $15.4,3.8$, and $12.7 \mathrm{nM}$, respectively). Compound 67 was able to induce apoptosis in $22 \mathrm{Rv} 1$ cells at low-micromolar concentration and revealed the S-phase arrest in cell cycle progression analysis. In contrast, 69 was non-cytotoxic against PC-3, LNCaP (androgensensitive human prostrate adenocarcinoma cells), and 22Rv1 cell line with $\mathrm{IC}_{50}>100 \mu \mathrm{M}$. Moreover, $22 \mathrm{Rv}$ cells treated with $100 \mu \mathrm{M}$ of 69 displayed only minimal induction of apoptosis as well as no significant changes in cell cycle progression [28].

A fungal bis-indolylbenzenoid, candidusin D (80) (Figure 10), was tested for its cytotoxic effects against eight cancer cell lines, viz. Hep G2 (human hepatocellular carcinoma), HT29 (human colorectal adenocarcinoma), HCT116 (human colorectal carcinoma), A549, A375 (human malignant melanoma), MCF7 (human mammary gland adenocarcinoma), U251 (human glioblastoma multiforme), and T98G (human glioblastoma astrocytoma) by the MTT assay. At $100 \mu \mathrm{M}$ concentration, 80 exhibited a significant decrease in cell viability in all cell lines tested except for T98G and HepG2. Compound 80 displayed $\mathrm{IC}_{50}$ values of $118.9,111.6,73.2,105.8,123.1,186.8$, and $212.5 \mu \mathrm{M}$ toward the Hep G2, HT29, HCT116, A549, A375, MCF7, and U251 cell lines, respectively. Doxorubicin, a positive control, showed IC 50 values of $0.12,0.63,0.29,0.24,0.05,0.36$, and $1.11 \mu \mathrm{M}$, respectively [33].

Penochalasins I (81), J (82) and K (83) (Figure 10) were evaluated for their cytotoxicity against human breast cancer cell line (MDA-MB-435), human gastric cancer cell line (SGC7901), and A549 by the MTT (3-(4,5-dimethylthiazol-2-yl)-2,5-diphenyl-2H-tetrazolium bromide) method. Compounds 81-83 exhibited a broad-spectrum inhibitory activity against all three cell lines. Compound 83 exhibited the strongest activity, with $\mathrm{IC}_{50}$ values of 4.65 , 5.52 , and $8.73 \mu \mathrm{M}$ toward MDA-MB-435, SGC-7901, and A549, respectively, followed by 81 with $\mathrm{IC}_{50}$ values of $7.55,7.32$, and $16.13 \mu \mathrm{M}$, respectively. Compound 82 displayed the weakest activity with $\mathrm{IC}_{50}$ values of $36.68,37.70$, and $35.93 \mu \mathrm{M}$, respectively $\left(\mathrm{IC}_{50}\right.$ values of epirubicin, a positive control, were $0.56,0.37$, and $0.61 \mu \mathrm{M}$, respectively) [34,35].

The chlorinated bis-indole alkaloids, dienomycin (119) and 6-methoxy- $7^{\prime}, 7^{\prime \prime}$-dichloroc hromopyrrolic acid (120) (Figure 13), were assayed for their cytotoxicity against MDA-MB435, MDA-MB-231 (human breast adenocarcinoma), NCI-H460 (human non-small-cell lung cancer), HCT-116, HepG2 cancer cell lines, and non-cancerous MCF10A (human breast epithelial) cells. Compound 119 showed stronger activity ( $\mathrm{IC}_{50}$ values of 3.9, 11.2, 3.6, 4.3 , and $8.2 \mu \mathrm{M}$, respectively) than 120 (IC 50 values of $19.4,>25,>25,13.1$, and $18.9 \mu \mathrm{M}$, respectively) against all the cancer cell lines but comparable activities against non-cancerous MCF10A cells ( $\mathrm{IC}_{50}$ values of 3.1 and $2.9 \mu \mathrm{M}$ ) (epirubicin was used as a positive control) [46].

The bromide salt of a synthetic version of tricepyridinium (122) (Figure 13) displayed cytotoxicity against murine leukemia P388 cells with an $\mathrm{IC}_{50}$ value of $1.0 \mu \mathrm{M}$. Comparison of the cytotoxicity among various synthetic analogs revealed that the presence of the indole group at the ethyl side chain of the pyridinium ring of $\mathbf{1 2 2}$ did not enhance cytotoxicity against P388 cells. This structure-activity relationship assessment indicated that the two indole moieties played a concerted role with the 1-ethylpyridinium moiety to induce cytotoxicity of P388 cells. [47].

The sponge-derived (+)-oxoaplysinopsin C (133a) and (-)-oxoaplysinopsin C (133b) (Figure 14) were tested for their cytotoxicity against the human cervical cancer (HeLa) cell line. Interestingly, 133a showed two-fold stronger activity $\left(\mathrm{IC}_{50}=27.0 \mu \mathrm{M}\right)$ than $\mathbf{1 3 3 b}$ $\left(\mathrm{IC}_{50}=61.6 \mu \mathrm{M}\right)$. Doxorubicin $\left(\mathrm{IC}_{50}=0.442 \mu \mathrm{M}\right)$ was used as a positive control [50].

Dragmacidins G (141) and H (142) (Figure 16), isolated from a marine sponge Lipastrotethya sp., showed toxicity against HeLa cells with $\mathrm{IC}_{50}$ values of $4.2 \mu \mathrm{M}$ and $4.6 \mu \mathrm{M}$, respectively [53]. Later on, 142, isolated from a deep-water marine sponge of an unidentified species of Spongosorites, was assayed against a panel of pancreatic cancer cell lines and exhibited a moderate cytotoxicity against PANC-1 (human pancreatic carcinoma), MIA PaCa-2 (human pancreatic carcinoma), BxPC-3 (human pancreatic adenocarcinoma), and ASPC-1 (human pancreatic adenocarcinoma) with $\mathrm{IC}_{50}$ values of $18 \mu \mathrm{M}, 26 \mu \mathrm{M}, 14 \mu \mathrm{M}$, and $27 \mu \mathrm{M}$, respectively [52]. Dragmacidins I (153) and J (154) (Figure 17) were assayed for their antiproliferative activity toward three human cancer cell lines: A549, HT29, and 
MDA-MB-231. Compounds 153 and $\mathbf{1 5 4}$ showed significant cytotoxicity against all of the tested cell lines. Compound 153 showed higher potency $\left(\mathrm{IC}_{50}\right.$ values of 2.7, 3.3, $\left.4.7 \mu \mathrm{M}\right)$ against A549, HT29, and MDA-MB-231 than 154 ( $\mathrm{IC}_{50}$ values of 4.7, 4.8, $\left.7.7 \mu \mathrm{M}\right)$. Moreover, a mitotic arrest in the metaphase in HeLa cells after treatment for $24 \mathrm{~h}$ of $\mathbf{1 5 3}$ and 154, at a concentration of $10 \mu \mathrm{M}$, was independent of the disorganization of the tubulin cytoskeleton. Moreover, A549 cells treated with 153 and $\mathbf{1 5 4}$ at a concentration of $10 \mu \mathrm{M}$ did not show any effect on their cytoskeleton and were not multinucleated. Furthermore, in the treatment with $10 \mu \mathrm{M}$ of 153 and 154 for 1, 6, and $24 \mathrm{~h}$, a continuous increment of the retinoblastoma protein (pRB) phosphorylation status in HeLa cells was observed, showing that 153 and 154 effectively inhibited PP1 and/or PP2A phosphatases. It is worth mentioning that pRB is an essential cell cycle controller that is regulated through dephosphorylation by PPs, PP1, and PP2A. Similar results were also observed in A549 cells where the hyperphosphorylation of pRB increased after 1 and $6 \mathrm{~h}$ of incubation, but subsequently diminished, resulting in a hypophosphorylated protein after $24 \mathrm{~h}$ [58].

Spongosoritins A-D (155-158) (Figure 17) displayed weak cytotoxicity against A549 and $\mathrm{K} 562$ (human immortalized myelogenous leukemia) cancer cell lines with $\mathrm{IC}_{50}$ values ranging from 24.2 to $77.3 \mu \mathrm{M}$ ( $\mathrm{IC}_{50}$ values of doxorubicin, a positive control, were 0.64 and $0.92 \mu \mathrm{M}$, respectively [59].

Securamines H-J (179-181) (Figure 18) were evaluated for the in vitro cytotoxicity against A2058 (melanoma), HT-29, and MCF-7 (breast adenocarcinoma) cancer cell lines as well as one non-malignant cell line (MRC-5, lung fibroblasts). Compounds $\mathbf{1 7 9}$ (IC 50 values of $1.4,1.9,2.1,2.7 \mu \mathrm{M})$ and $180\left(\mathrm{IC}_{50}\right.$ values of $\left.2.7,2.5,2.4,5.3 \mu \mathrm{M}\right)$ showed potent cytotoxicity against all the tested cell lines whereas 181 displayed no significant activity at the highest concentration tested $(50 \mu \mathrm{M})$. The authors concluded that a double bond between C-2 and C-3 is crucial for the cytotoxicity. Compound $\mathbf{1 7 9}$ was evaluated for the cell death kinetics by treating A2058, HT-29, MCF-7, and MRC- 5 cells with different concentrations of $\mathbf{1 7 9}$ for 4, 24, 48, and $72 \mathrm{~h}$. Since the $\mathrm{IC}_{50}$ values decreased with increasing exposure times, it was concluded that the cytotoxic activity of $\mathbf{1 7 9}$ was time-dependent [64].

\subsection{Anti-Inflammatory Activity}

Asperversamides F-H (17-19) (Figure 4) and asperversamides A-E (34-38) (Figure 6) were assayed for their inhibitory effects on inducible nitric oxide synthase (iNOS) and nitic oxide (NO) production. However, only 17, 18, 35, and 36 exhibited potential iNOS inhibitory activities with $\mathrm{IC}_{50}$ values of $13.86,5.39,9.95$, and $16.58 \mu \mathrm{M}$, respectively (the $\mathrm{IC}_{50}$ value of a positive control, MG132, was $0.24 \mu \mathrm{M}$ ) and inhibited the release of $\mathrm{NO}$ in lipopolysaccharide (LPS)-induced Raw264.7 cells, with $\mathrm{IC}_{50}$ values of 23.72, 11.17, 17.24, and $25.09 \mu \mathrm{M}$, respectively (the $\mathrm{IC}_{50}$ value of a positive control, MG132, was $0.17 \mu \mathrm{M}$ ). Since the tested compounds exhibited weak activity $\left(\mathrm{IC}_{50}\right.$ values more than $\left.100 \mu \mathrm{M}\right)$ against Raw264.7 cells, their inhibitory effects were not related to cell viability. Moreover, molecular docking studies between $\mathbf{1 8}$ and iNOS revealed that $\mathbf{1 8}$ adopted an extended conformation and fit well into the ligand binding site of the mutant iNOS. Moreover, hydrogen bonds were predicted between the carbonyl (C-12) and Asn115 as well as between the carbonyl (C-18) and $\mathrm{Gln} 257$, in addition to a possible $\pi-\pi$ stacking interaction between the diketopiperazine or the double bond at C-10 and the HEME. The results of molecular docking led the authors to conclude that the planarity of the molecule is important for its binding capacity, as this conformation provides enough space for the two carbonyls to form strong hydrogen bonds with the HEME [18].

Asperthins A (41), E (45), and F (46) (Figure 6) were assayed for their anti-inflammatory activity in the Propionibacterium acnes-induced human monocyte cell line (THP-1) by measuring the secretion of inflammatory factor 1L-1 $\beta$ by THP-1 cells using the ELISA method. Compounds $\mathbf{4 1}, \mathbf{4 5}$, and 46 displayed moderate inti-inflammatory activity with $\mathrm{IC}_{50}$ values of $1.46,30.5$, and $37.2 \mu \mathrm{M}$, respectively (a positive control, tretinoin, showed $\mathrm{IC}_{50}=3.38 \mu \mathrm{M}$ ). Parallel to the $\mathrm{IC}_{50}$ values, the safety concentration ranges of 41,45 , and 46 , which caused over $80 \%$ of cell viability of THP-1 cells, were $0-5,0-40$, and $0-50 \mu \mathrm{M}$, respectively [22]. 
Sponge-derived diketopiperazine-containing bromooxindoles, geobarrettins A-C (138-140) (Figure 15), were assayed for their anti-inflammatory activity on human dendritic cell (DC) secretion of pro-inflammatory cytokine IL-12p40 and anti-inflammatory cytokine IL-10 production. At a concentration of $10 \mu \mathrm{g} / \mathrm{mL}$, during $24 \mathrm{~h}, 139$ decreased DC secretion of IL-12p 40 by $29 \%$ without affecting the secretion of IL- 10 while 140 slightly decreased the DC secretion of IL-12p 40 by $13 \%$ but increased IL- 10 production by $40 \%$. Moreover, it was found that the effects of $\mathbf{1 3 9}$ and $\mathbf{1 4 0}$ on IL-12p40 and IL-10 secretion by DCs were not dose-dependent, although 139 showed a tendency of an increasing effect on the secretion of IL-12p40 at higher concentrations. To further elucidate the anti-inflammatory activity of the compounds, DCs matured in the presence of 139 and 140 were co-cultured with allogeneic $\mathrm{CD}^{+} \mathrm{T}$ cells and the differentiation of the $\mathrm{T}$ cells was investigated by determination of the secretion of the cytokines IL-10, IL-17, and IFN- $\gamma$. It was found that T cells co-cultured with DCs matured in the presence of $\mathbf{1 3 9}$ and $\mathbf{1 4 0}$ secreted less IL-10 and IFN- $\gamma$ than T cells co-cultured with DCs matured without the compounds, however, maturing DCs in the presence of $\mathbf{1 3 9}$ and $\mathbf{1 4 0}$ did not affect T cell secretion of IL-17 [51].

The prenylated indoles, flustramines $\mathrm{Q}-\mathrm{W}(\mathbf{1 6 6 - 1 7 2})$ and flustraminols $\mathrm{C}-\mathrm{H}(\mathbf{1 7 3}-\mathbf{1 7 8})$ (Figure 18), were evaluated for their anti-inflammatory activities by evaluating their effects, at a concentration of $10 \mu \mathrm{g} / \mathrm{mL}$, on DC secretion of the cytokines IL-12p40 and IL-10 and comparing them to the effect of solvent alone. This model is based on the fact that if a compound either decreases DC secretion of IL-12 or increases secretion of IL-10, it is considered to have an anti-inflammatory effect. The results showed that 166, 168, 170, and 178 decreased DC secretion of the pro-inflammatory cytokine IL-12p40 in the range of 32\% to $55 \%$ whereas 169 increased DC secretion of the anti-inflammatory cytokine IL-10 by $19-30 \%$, and therefore had modest anti-inflammatory effects. Since none of the active compounds affected the viability of DCs at $10 \mu \mathrm{g} / \mathrm{mL}$, it was concluded that the decrease in IL12p40 secretion was not due to impaired cell viability [63].

\subsection{Antidiabetic Activity}

Scequinadoline J (6) (Figure 3) was screened for its potentiality as an anti-diabetes mellitus type 2 (T2DM) agent by using the 3T3-L1 fibroblast cell line. Compound 6 was found to promote triglyceride (TG) accumulation in 3T3-L1 cells with an $\mathrm{EC}_{50}$ value of $1.03 \mu \mathrm{M}$ (rosiglitazone, a clinically used medication for T2DM, was used as a positive control and showed an $\mathrm{EC}_{50}$ value of $0.12 \mu \mathrm{M}$ ). Moreover, 6 did not show cytotoxicity against 3T3-L1 cells at a concentration of $50 \mu \mathrm{M}$. Furthermore, it was found that 6 promoted TG accumulation mainly by facilitating adipogenesis and not lipogenesis, which is similar to rosiglitazone [11].

The enzymes protein tyrosine phosphatases (PTPs), which catalyze the dephosphorylation of phosphorylated protein molecules, are essential regulators of signal transduction pathways, which are associated with diabetes, cancer, autoimmune disease, and other diseases. Therefore, they are thought to be promising targets for drug discovery, especially for diabetes. For these reasons, penerpenes A-I (50-58) (Figure 7) were assayed for their inhibitory activities against PTPs including non-transmembrane PTPs (PTP1B and TCPTP), receptor-like PTP (PTPsigma), and dual-specificity phosphatases (VHR). Compounds 50 $\left(\mathrm{IC}_{50}=1.7\right.$ and $5.0 \mu \mathrm{M}$ against $\mathrm{PTP} 1 \mathrm{~B}$ and TCPTP, respectively $)$ and $51\left(\mathrm{IC}_{50}=2.4\right.$ and $4.5 \mu \mathrm{M}$, respectively) displayed inhibitory activities with potencies comparable to that of $\mathrm{Na} 3 \mathrm{VO} 4\left(\mathrm{IC}_{50}=1.6\right.$ and $2.4 \mu \mathrm{M}$, respectively) while $54\left(\mathrm{IC}_{50}=14 \mu \mathrm{M}\right.$ against PTP1B), 55 $\left(\mathrm{IC}_{50}=27 \mu \mathrm{M}\right.$ against PTP1B $)$, and $57\left(\mathrm{IC}_{50}=23\right.$ and $25 \mu \mathrm{M}$ against PTP1B and TCPTP) were ca. ten-fold less active than $\mathrm{Na} 3 \mathrm{VO} 4\left(\mathrm{IC}_{50}=2\right.$ and $2 \mu \mathrm{M}$, respectively). On the other hand, $50\left(\mathrm{IC}_{50}=29\right.$ and $>30 \mu \mathrm{M}$, respectively) and $51\left(\mathrm{IC}_{50}=>30 \mu \mathrm{M}\right)$ exhibited weak activity against PTPsigma and VHR when compared to Na3VO4 $\left(\mathrm{IC}_{50}=9.7\right.$ and $13.2 \mu \mathrm{M}$, respectively) while 57 was only weakly active against PTPsigma with $\mathrm{IC}_{50}=38 \mu \mathrm{M}$ ( IC $_{50}$ of $\mathrm{Na} 3 \mathrm{VO} 4=10 \mu \mathrm{M})[24,25]$. Docking study suggested that $\mathbf{5 0}$ binds deep in the active site pocket and forms hydrogen bonds with Asp 181 and Gln 262. However, with a larger ring structure, $\mathbf{5 1}$ did not bind at the active site but instead interacted with Phe 30 in the 
so-called secondary binding site of PTP1B [25]. SF5280-415 (116) (Figure 12) displayed an inhibitory effect against PTP1B, a promising therapeutic target for the treatment of diabetes and obesity, with an $\mathrm{IC}_{50}$ value of $14.2 \mu \mathrm{M}$ [43].

Since hypoadiponectinemia is a major symptom of diverse human metabolic diseases such as obesity, type 2 diabetes, atherosclerosis, and non-alcoholic steatohepatitis, compounds that stimulate adiponectin secretion could be promising for the treatment of metabolic diseases such as T2DM. For these reasons, psammocindoles A-C (123-125) (Figure 14) were evaluated for the adiponectin-secretion-stimulating activities in hBMMSCs using an adipogenic cocktail consisting of insulin, dexamethasone, and isobutyl methylxanthine (IDX). Compounds 123-125 (at $10 \mu \mathrm{M}$ ) significantly increased adiponectin secretion during adipogenesis in hBM-MSCs compared to that in the IDX control. In a concentration-response analysis, $\mathbf{1 2 3}$ and $\mathbf{1 2 4}$ were found to be more potent $\left(\mathrm{EC}_{50}=9.86\right.$ and $6.20 \mu \mathrm{M}$, respectively) than bezafibrate $\left(\mathrm{EC}_{50}>10 \mu \mathrm{M}\right)$, a currently prescribed pan-PPAR agonist, while 125 was less potent $\left(\mathrm{EC}_{50}>10 \mu \mathrm{M}\right)$. Moreover, 123 and 124 also increased the lipid accumulation in differentiated adipocytes in hBM-MSCs compared to that of the IDX control, suggesting that, similar to pioglitazone, $\mathbf{1 2 3}$ and $\mathbf{1 2 4}$ are able to improve insulin sensitivity. Thus, these compounds could represent a novel pharmacophore for the development of therapeutic agents for the treatment of human metabolic diseases [48] ( \pm )-Oxoaplysinopsin B (132a/132b) (Figure 14) showed inhibitory activity against PTP1B with an $\mathrm{IC}_{50}$ value of $20.8 \mu \mathrm{M}$. Interestingly, the optically pure (+)-132a was more potent $\left(\mathrm{IC}_{50}=18.3 \mu \mathrm{M}\right)$ than both the racemate and $(-)-\mathbf{1 3 2 a}\left(\mathrm{IC}_{50}=26.5 \mu \mathrm{M}\right)[50]$.

\subsection{Antiparasitic Activity}

Dragmacidin G (141) (Figure 16) was assayed against a chloroquine-resistant (DD2) Plasmodium falciparum strain and displayed a modest inhibitory activity with $\mathrm{IC}_{50}=6.4 \mu \mathrm{M}$. The selectivity determination using the MTS [(3-(4,5-dimethylthiazol-2-yl)-5-(3-carboxyme thoxyphenyl)-2-(4-sulfophenyl)-2H-tetrazolium)] assay showed that 141 was almost equally cytotoxic to the $\mathrm{NIH} 3 \mathrm{~T} 3$ mouse fibroblast cell line $\left(\mathrm{IC}_{50}=7.8 \mu \mathrm{M}\right)$, indicating no selectivity for the malaria parasite [52].

5-Bromotrisindoline (162) and 6-bromotrisi3ndoline (163) (Figure 17) were evaluated for their antitrypanosomal activity against Trypanosoma brucei that causes African trypanosomiasis, also known as sleeping sickness. Compounds 162 and 163 demonstrated moderate antitrypanosomal activity after 48 and $72 \mathrm{~h}$, with $\mathrm{IC}_{50}$ values of $15.36(48 \mathrm{~h})$ and $13.47(72 \mathrm{~h})$, and $12.35(48 \mathrm{~h})$, and $10.27(72 \mathrm{~h}) \mu \mathrm{M}$, respectively [60],

\subsection{Neuroprotective Activity}

The deoxyisoaustamide derivatives 24-30 (Figure 5) were examined for their potential protective effects against the acute toxicity of paraquat $(\mathrm{PQ})$ in murine neuroblastoma Neuro-2a cells. Treatment of Neuro-2a cells with $500 \mu \mathrm{M}$ of PQ induced a decrease in cell viability by $51.8 \%$. However, co-treatment with $1 \mu \mathrm{M}$ of 27 and 29 increased a viability of PQ-treated cells by $38.6 \%$ and $30.3 \%$, respectively, whereas 28 increased a viability of the cells by $36.5 \%$ and $39.4 \%$ at concentrations of $1 \mu \mathrm{M}$ and $10 \mu \mathrm{M}$, respectively. Moreover, 27 , 28, and 29 were not cytotoxic to Neuro-2a cells [17].

\subsection{Enzyme Inhibitors}

Guitarrins A-E (126-130) (Figure 14) were assayed for the inhibitory activity against the enzyme alkaline phosphatase (ALP) from the marine bacterium Cobetia marina. Reasons for interest in this ALP are its possible application as a tool for structural and functional studies of nucleic acids as well as for the preparation of Ig-enzyme conjugates for immunologic assays. ALP produced by C. marina was found to have very high specific activity. Compound 128 was found to be a potent inhibitor of ALP from C. marina with an $\mathrm{IC}_{50}$ value of $2.0 \mu \mathrm{M}$ when compared to a positive control, ethylenediaminetetraacetic acid (EDTA, $\mathrm{IC}_{50}=80,000 \mu \mathrm{M}$ ), which is the most active inhibitor of $C$. marina alkaline phos- 
phatase (CmAP) described to date. On the other hand, 129 showed weak inhibitory activity $\left(\mathrm{IC}_{50}=100 \mu \mathrm{M}\right)$ whereas 126, 127, and $\mathbf{1 3 0}$ did not inhibit this enzyme [49].

\subsection{Other Activities}

Dinotoamide J (73) (Figure 9) was tested for its pro-angiogenic activity in a vatalanib (PTK787)-induced vascular injury zebrafish model. At a concentration of $70 \mu \mathrm{g} / \mathrm{mL}, 73$ exhibited a significant effect in a dose-dependent manner. Ginsenoside $\operatorname{Rg} 1(120 \mu \mathrm{g} / \mathrm{mL})$ was used as a positive control [30].

In order to facilitate the localization of the bioactive indole alkaloids from different sources and their biological and pharmacological activities, the source organisms, biological/pharmacological activities, compound numbers, and the references cited are summarized in Table 1.

Table 1. Summary of source organisms, biological/pharmacological activities, compound numbers, and the cited references.

\begin{tabular}{|c|c|c|c|}
\hline Organisms & Biological/Pharmacological Activities & Compound & Reference \\
\hline \multicolumn{4}{|c|}{ 1. Marine-derived fungi } \\
\hline \multicolumn{4}{|c|}{ Antibacterial activity } \\
\hline Aspergillus sp. YJ191021 & $\begin{array}{c}\text { Xanthomonas oryzae pv. oryzae } \\
\text { X. oryzae pv. Oryzicola } \\
\text { Edwardsiella tarda } \\
\text { Vibrio anguillarum } \\
\text { V. parahaemolyticus } \\
\text { Aeromonas hydrophilia }\end{array}$ & 41 & [22] \\
\hline A. fumigatus SCSIO 41012 & $\begin{array}{c}\text { Acinetoobacter baumannii ATCC } 19606, \\
\text { A. baumannii ATCC 15122, } \\
\text { Klebsiella pneumoniae ATCC } 14578 \\
\text { Staphylococcus aureus ATCC } 16339\end{array}$ & 93 & [41] \\
\hline \multicolumn{4}{|c|}{ Antibiofilm activity } \\
\hline Eurotium chevalieri KUFA 0006 & S. aureus ATCC 25923 & 9 & [14] \\
\hline \multicolumn{4}{|c|}{ Anti-Quorum sensing activity } \\
\hline Aspergillus sp. HNMF114 & Chromobacterium violaceum CV026 & 91,92 & [40] \\
\hline \multicolumn{4}{|c|}{ Antifungal activity } \\
\hline Aspergillus sp. YJ191021 & Rhizoctonia solani & 45 & [22] \\
\hline A. fumigatus SCSIO 41012 & $\begin{array}{l}\text { Fusarium oxysporum f. sp. cucumerinum } \\
\text { F. oxysporum f. sp. momordicae }\end{array}$ & 93 & [41] \\
\hline Penicillium chrysogenum V11 & $\begin{array}{c}\text { Colletotrichum gloeosporioides } \\
\text { R. solani }\end{array}$ & 82,83 & {$[34,35]$} \\
\hline \multicolumn{4}{|c|}{ Antiviral activity } \\
\hline Fusarium sp. L1 & Anti-Zika virus & $48,49,74,75$ & [7] \\
\hline A. candidus HDN15-152 & Anti-influenza A virus (H1N1) & 65 & [27] \\
\hline P. raistrickii IMB17-034 & Anti-hepatitis $C$ virus & 90 & [39] \\
\hline Scedosporium apiospermum F41 & Anti-hepatitis $C$ virus & 106,114 & [12] \\
\hline \multicolumn{4}{|c|}{ Anticancer activity } \\
\hline Aspergillus sp. KMM4676 & 22Rv1, PC-3, and LNCaP & 66,67 & [28] \\
\hline A. candidus KUFA0062 & Hep G2, HT29, HCT116, A549, A375, MCF7 and U251 & 80 & [33] \\
\hline P. chrysogenum V11 & MDA-MB-435, SGC-7901,A549 & 81,83 & {$[34,35]$} \\
\hline
\end{tabular}


Table 1. Cont.

\begin{tabular}{|c|c|c|c|}
\hline Organisms & Biological/Pharmacological Activities & Compound & Reference \\
\hline \multicolumn{4}{|c|}{ 1. Marine-derived fungi } \\
\hline \multicolumn{4}{|c|}{ Anti-inflammatory activity } \\
\hline Aspergillus versicolor & iNOS inhibitory activity & $17,18,35,36$ & [18] \\
\hline Aspergillus sp. YJ191021 & Inhibit secretion of $1 \mathrm{~L}-1 \beta$ by THP- 1 cells & $41,45,46$ & [22] \\
\hline \multicolumn{4}{|c|}{ Antidiabetic activity } \\
\hline S. apiospermum F41-1 & promote triglyceride accumulation in 3T3-L1 & 6 & [12] \\
\hline Penicillium sp. KFD28 & Inhibition of protein tyrosine & $50,51,54$ & {$[24]$} \\
\hline \multirow{2}{*}{ Aspergillus sp. SF-5280 } & phosphatases (PTPs) & 55,57 & [25] \\
\hline & Inhibition of non-transmembrane PTPs (PTP1B) & 116 & [43] \\
\hline \multicolumn{4}{|c|}{ Neuroprotective activity } \\
\hline P. dimorphosporum KMM 4689 & increased a viability of paraquat-treated cells & 27,29 & [30] \\
\hline \multicolumn{4}{|c|}{ Pro-angiogenic activity } \\
\hline A. austroafricanus Y32-2 & $\begin{array}{c}\text { Pro-angiogenic activity in a vatalanib (PTK787)-induced } \\
\text { vascular injury zebrafish model }\end{array}$ & 73 & {$[30]$} \\
\hline \multicolumn{4}{|c|}{ 2.Marine-derived bacteria } \\
\hline \multicolumn{4}{|c|}{ Antibacterial activity } \\
\hline Streptomyces sp. SCSIO 11791 & $\begin{array}{l}\text { Micrococcus luteus ML01, S. aureus ATCC 29213, and a } \\
\text { panel of MRSA isolated from human patients (MRSA } \\
\text { 991, MRSA 1862, MRSA 669 A, MRSA A2) and pig } \\
\text { (MRSA GDQ6P012P, MRSA GDE4P037P) }\end{array}$ & 119,120 & [46] \\
\hline Acinetobacter sp. ZZ1275 & S. aureus (MRSA), E. coli & 118,121 & [45] \\
\hline $\begin{array}{l}\text { E. coli transfected by } \\
\text { metagenomic DNA prepared } \\
\text { from the marine sponge } \\
\text { Dicderma calyx }\end{array}$ & Bacillus cereus, S. aureus (MSSA) & 122 & [47] \\
\hline \multicolumn{4}{|c|}{ Antifungal activity } \\
\hline Acinetobacter sp. ZZ1275 & Candida albicans & 118,121 & [45] \\
\hline \multicolumn{4}{|c|}{ Anticancer activity } \\
\hline Streptomyces sp. SCSIO 11791 & $\begin{array}{c}\text { MDA-MB-435, MDA-MB-231 NCI-H460, HCT-116, } \\
\text { HepG2. MCF10A }\end{array}$ & 119,120 & [46] \\
\hline \multicolumn{4}{|c|}{ 3.Marine sponges } \\
\hline \multicolumn{4}{|c|}{ Antibacterial activity } \\
\hline Spongosorites sp. & Mycobacterium tuberculosis CDC1551 & 141 & [52] \\
\hline \multirow{2}{*}{ Spongosorites sp. } & S. aureus & $156-158,159$ & [59] \\
\hline & S. entérica & 158,159 & [59] \\
\hline Topsentia sp. & S. aureus ATCC 29213 & 143,161 & [54] \\
\hline Callyspongia siphonella & S. aureus and B. subtilis & 162,163 & [60] \\
\hline Myrmekioderma sp. & E. coli and B. subtilis & 164 & [67] \\
\hline \multicolumn{4}{|c|}{ Antiviral activity } \\
\hline Topsentia sp. & Anti-HIV activity & 143,161 & [54] \\
\hline
\end{tabular}


Table 1. Cont.

\begin{tabular}{|c|c|c|c|}
\hline Organisms & Biological/Pharmacological Activities & Compound & Reference \\
\hline \multicolumn{4}{|c|}{ 3.Marine sponges } \\
\hline \multicolumn{4}{|c|}{ Anticancer activity } \\
\hline Fascaplysinopsis reticulata & $\mathrm{HeLa}$ & $133 a, 133 b$ & [50] \\
\hline Spongosorites sp. & $\begin{array}{l}\text { Human pancreatic cell lines: PANC-1, MIA PaCa-2, } \\
\text { BxPC-3, ASPC-1 }\end{array}$ & 141 & [52] \\
\hline Dragmacidon sp. & A549, HT29, and MDA-MB-231 & 153,154 & {$[58]$} \\
\hline Spongosorites sp. & A549 and K562 & $155-158$ & [59] \\
\hline \multicolumn{4}{|c|}{ Anti-inflammatory activity } \\
\hline Geodia barretti & $\begin{array}{l}\text { Decrease dendritic cell secretion of pro-inflammatory } \\
\text { cytokine IL-12p40 and anti-inflammatory cytokine IL-10 } \\
\text { production }\end{array}$ & 139,140 & [59] \\
\hline \multicolumn{4}{|c|}{ Antidiabetic activity } \\
\hline Psammocinia vermis & $\begin{array}{l}\text { Increase adiponectin secretion during adipogenesis in } \\
\text { hBM-MSCs }\end{array}$ & $123-125$ & [48] \\
\hline Fascaplysinopsis reticulata & inhibitory activity against PTP1B & $132 a, 132 b$ & [50] \\
\hline \multicolumn{4}{|c|}{ Antiparasitic activity } \\
\hline Callyspongia siphonella & Antitrypanosomal activity against Trypanosoma brucei & 162,163 & [60] \\
\hline \multicolumn{4}{|c|}{ Enzyme inhibitors } \\
\hline Guitarra fimbriata & Inhibitor of alkaline phosphatase & 128 & {$[49]$} \\
\hline Spongosorites sp. & Inhibit sortase A & $156,157,159,160$ & [59] \\
\hline \multicolumn{4}{|c|}{ 4.Bryozoans } \\
\hline \multicolumn{4}{|c|}{ Anticancer activity } \\
\hline Securiflustra securifrons & A2058, HT-29, MCF-7, MRC-5 & 179,180 & [64] \\
\hline \multicolumn{4}{|c|}{ Anti-inflammatory activity } \\
\hline Flustra foliácea & $\begin{array}{l}\text { Decrease DC secretion of the pro-inflammatory cytokine } \\
\text { IL-12p40 }\end{array}$ & $166,168,170,178$ & [63] \\
\hline \multicolumn{4}{|c|}{ 5.Algae } \\
\hline \multicolumn{4}{|c|}{ Antibacterial activity } \\
\hline Laurencia similis & $\begin{array}{c}\text { S. aureus, B. subtilis, B. thuringensis, Pseudomonas } \\
\text { lachrymans, Agrobacterium tumefaciens, Xanthomonas } \\
\text { vesicatória, Ralstonia solanacearum }\end{array}$ & 182,183 & [65] \\
\hline
\end{tabular}

\section{Conclusions}

Marine organisms have been proven to be valuable sources of structurally diverse and unique indole compounds. Their structures vary from simple to complex and incorporate different types of compounds ranging from simple prenyl groups to diterpene moieties or other molecules or scaffolds such as pyrazine, diketopiperazine, guanidine, and quinazoline. The indole ring system can be present as an intact indole or undergoes oxidation or/and rearrangements to form different scaffolds or even incorporate a nitrogen atom to form azaindole derivatives or halogen and sulfur atoms to form bromoindoles, sulfonyl, and sulfinyl side chains. Moreover, these marine-derived indoles can have a single indole unit or contain two or three indole units as found in bis-indoles, tris-indoles, homo-, and heterodimers of indole compounds. This structural diversity of marine-derived indoles is reflected by a variety of biological and pharmacological activities that they manifest such as antibacterial, antiviral, anticancer, antiparasitic activities, and enzyme inhibition. Thus, marine-derived indole compounds are excellent sources to be explored for pharmacophores 
to serve for the development of drug leads or even therapeutic agents for the treatments of infectious diseases, cancer, or even some metabolic diseases.

Author Contributions: Conceptualization, M.Y.P., J.T.W. and A.K.; Resources, M.Y.P., J.T.W., P.A., A.B. and S.I.R.; Writing-original draft preparation, M.Y.P., J.T.W. and P.A.; Writing-review and editing, M.Y.P., J.T.W., P.A., A.B., S.I.R. and A.K.; Visualization, J.T.W., A.B. and P.A.; Supervision, M.Y.P. and A.K.; Project administration, M.Y.P. and S.I.R. All authors have read and agreed to the published version of the manuscript.

Funding: This research was funded by the Indonesian Institute of Sciences through the DIPA 2021 Research Fund B-10405/IPH/HK.01.03/XI/2020 and also by the structured program of the R\&D\&I ATLANTIDA-Platform for the monitoring of the North Atlantic Ocean and tools for the sustainable exploitation of marine resources (reference NORTE-01-0145-FEDER-000040), supported by the North Portugal Regional Operational Program (NORTE2020) through the European Regional Development Fund (ERDF).

Acknowledgments: We would like to thank the Head of the Research Center for Biotechnology, Life Sciences Research Organization, National Research and Innovation Agency (BRIN) as well as the research and administration staff members for their support. A.K. thanks the Instituto de Ciências Biomédicas Abel Salazar of the University of Porto for the logistical support. All authors from the Research Center for Biotechnology, Life Sciences Research Organization, National Research and Innovation Agency (BRIN) are supported by the DIPA 2021 Research Fund.

Conflicts of Interest: The authors declare no conflict of interest.

\section{References}

1. Harvey, A.L.; Edrada-Ebel, R.; Quinn, R.J. The re-emergence of natural products for drug discovery in the genomics era. Nat. Rev. Drug Discov. 2015, 14, 111-129. [CrossRef] [PubMed]

2. Newman, D.J.; Cragg, G.M. Drugs and drug candidates from marine sources: An assessment of the current "state of play". Planta Med. 2016, 82, 775-789. [CrossRef] [PubMed]

3. Gul, W.; Hamann, M.T. Indole alkaloid marine natural products: An established source of cancer drug leads with considerable promise for the control of parasitic, neurological and other diseases. Life Sci. 2005, 78, 442-453. [CrossRef] [PubMed]

4. França, P.H.; Barbosa, D.P.; da Silva, D.L.; Ribeiro, Ê.A.; Santana, A.E.; Santos, B.V.; Barbosa-Filho, J.M.; Quintans, J.S.; Barreto, R.S.; Quintans-Júnior, L.J. Indole alkaloids from marine sources as potential leads against infectious diseases. BioMed Res. Int. 2014, 2014, 375423. [CrossRef]

5. Netz, N.; Opatz, T. Marine indole alkaloids. Mar. Drugs 2015, 13, 4814-4914. [CrossRef]

6. Kochanowska-Karamyan, A.J.; Hamann, M.T. Marine indole alkaloids: Potential new drug leads for the control of depression and anxiety. Chem. Rev. 2010, 110, 4489-4497. [CrossRef]

7. Guo, Y.W.; Liu, X.J.; Yuan, J.; Li, H.J.; Mahmud, T.; Hong, M.J.; Yu, J.C.; Lan, W.J. 1-Tryptophan induces a marine-derived Fusarium sp. to produce indole alkaloids with activity against the Zika virus. J. Nat. Prod. 2020, 83, 3372-3380. [CrossRef]

8. Chen, Y.X.; Xu, M.Y.; Li, H.J.; Zeng, K.J.; Ma, W.Z.; Tian, G.B.; Xu, J.; Yang, D.P.; Lan, W.J. Diverse secondary metabolites from the marine-derived fungus Dichotomomyces cejpii F31-1. Mar. Drugs 2017, 15, 339. [CrossRef]

9. Wang, K.T.; Xu, M.Y.; Liu, W.; Li, H.J.; Xu, J.; Yang, D.P.; Lan, W.J.; Wang, L.Y. Two additional new compounds from the marine-derived fungus Pseudallescheria ellipsoidea F42-3. Molecules 2016, 21, 442. [CrossRef]

10. Meng, L.H.; Chen, H.Q.; Form, I.; Konuklugil, B.; Proksch, P.; Wang, B.G. New chromone, isocoumarin, and indole alkaloid derivatives from three sponge-derived fungal strains. Nat. Prod. Commun. 2016, 11, 1293-1296. [CrossRef]

11. Li, C.J.; Chen, P.N.; Li, H.J.; Mahmud, T.; Wu, D.L.; Xu, J.; Lan, W.J. Potential antidiabetic fumiquinazoline alkaloids from the marine-derived fungus Scedosporium apiospermum F41-1. J. Nat. Prod. 2020, 83, 1082-1091. [CrossRef]

12. Huang, L.H.; Xu, M.Y.; Li, H.J.; Li, J.Q.; Chen, Y.X.; Ma, W.Z.; Li, Y.P.; Xu, J.; Yang, D.P.; Lan, W.J. Amino acid-directed strategy for inducing the marine-derived fungus Scedosporium apiospermum F41-1 to maximize alkaloid diversity. Org. Lett. 2017, 19, 4888-4891. [CrossRef]

13. May Zin, W.W.; Buttachon, S.; Dethoup, T.; Fernandes, C.; Cravo, S.; Pinto, M.M.M.; Gales, L.; Pereira, J.A.; Silva, A.M.S.; Sekeroglu, N.; et al. New cyclotetrapeptides and a new diketopiperzine derivative from the marine sponge-associated fungus Neosartorya glabra KUFA 0702. Mar. Drugs 2016, 14, 136. [CrossRef] [PubMed]

14. May Zin, W.W.; Buttachon, S.; Dethoup, T.; Pereira, J.A.; Gales, L.; Inácio, Â.; Costa, P.M.; Lee, M.; Sekeroglu, N.; Silva, A.M.S.; et al. Antibacterial and antibiofilm activities of the metabolites isolated from the culture of the mangrove-derived endophytic fungus Eurotium chevalieri KUFA 0006. Phytochemistry 2017, 141, 86-97. [CrossRef]

15. Zhong, W.M.; Wang, J.F.; Shi, X.F.; Wei, X.Y.; Chen, Y.C.; Zeng, Q.; Yao Xiang, Y.; Chen, X.Y.; Tian, X.P.; Xiao, Z.H.; et al. Eurotiumins A-E, five new alkaloids from the marine-derived fungus Eurotium sp. SCSIO F452. Mar. Drugs 2018, 16, 136. [CrossRef] 
16. Wei, X.; Feng, C.; Wang, S.Y.; Zhang, D.M.; Li, X.H.; Zhang, C.X. New indole diketopiperazine alkaloids from soft coral-associated epiphytic fungus Aspergillus sp. EGF 15-0-3. Chem. Biodivers. 2020, 17, e2000106. [CrossRef] [PubMed]

17. Afiyatullov, S.H.; Zhuravleva, O.I.; Antonov, A.S.; Berdyshev, D.V.; Pivkin, M.V.; Denisenko, V.A.; Popov, R.S.; Gerasimenko, A.V.; von Amsberg, G.; Dyshlovoy, S.A.; et al. Prenylated indole alkaloids from co-culture of marine-derived fungi Aspergillus sulphureus and Isaria felina. J. Antibiot. 2018, 71, 846-853. [CrossRef]

18. Li, H.; Sun, W.; Deng, M.; Zhou, Q.; Wang, J.; Liu, J.; Chen, C.; Qi, C.; Luo, Z.; Xue, Y.; et al. Asperversiamides, linearly fused prenylated indole alkaloids from the marine-derived fungus Aspergillus versicolor. J. Org. Chem. 2018, 83, 8483-8492. [CrossRef] [PubMed]

19. Lan, W.J.; Wang, K.T.; Xu, M.Y.; Zhang, J.J.; Lam, C.K.; Zhong, G.H.; Xu, J.; Yang, D.P.; Li, H.J.; Wang, L.Y. Secondary metabolites with chemical diversity from the marine-derived fungus Pseudallescheria boydii F19-1 and their cytotoxic activity. RSC Adv. 2016, 6, 76206-76213. [CrossRef]

20. Zhuravleva, O.I.; Antonov, A.S.; Trang, V.T.D.; Pivkin, M.V.; Khudyakova, Y.V.; Denisenko, V.A.; Popov, R.S.; Kim, N.Y.; Yurchenko, E.A.; Gerasimenko, A.V.; et al. New deoxyisoaustamide derivatives from the coral-derived fungus Penicillium dimorphosporum KMM 4689. Mar. Drugs 2021, 19, 32. [CrossRef]

21. Xu, X.; Zhang, X.; Nong, X.; Wang, J.; Qi, S. Brevianamides and mycophenolic acid derivatives from the deep-sea-derived fungus Penicillium brevicompactum DFFSCS025. Mar. Drugs 2017, 15, 43. [CrossRef] [PubMed]

22. Yang, J.; Gong, L.; Guo, M.; Jiang, Y.; Ding, Y.; Wang, Z.; Xin, X.; An, F. Bioactive indole diketopiperazine alkaloids from the marine endophytic fungus Aspergillus sp. YJ191021. Mar. Drugs 2021, 19, 157. [CrossRef] [PubMed]

23. Zheng, Y.Y.; Shen, N.X.; Liang, Z.Y.; Shen, L.; Chen, M.; Wang, C.Y. Paraherquamide J, a new prenylated indole alkaloid from the marine-derived fungus Penicillium janthinellum HK1-6. Nat. Prod. Res. 2020, 34, 378-384. [CrossRef]

24. Kong, F.D.; Fan, P.; Zhou, L.M.; Ma, Q.Y.; Xie, Q.Y.; Zheng, H.Z.; Zheng, Z.H.; Zhang, R.S.; Yuan, J.Z.; Dai, H.F.; et al. Penerpenes A-D, four indole terpenoids with potent protein tyrosine phosphatase inhibitory activity from the marine-derived fungus Penicillium sp. KFD28. Org. Lett. 2019, 21, 4864-4867. [CrossRef]

25. Zhou, L.M.; Kong, F.D.; Fan, P.; Ma, Q.Y.; Xie, Q.Y.; Li, J.H.; Zheng, H.Z.; Zheng, Z.H.; Yuan, J.Z.; Dai, H.F.; et al. Indolediterpenoids with protein tyrosine phosphatase inhibitory activities from the marine-derived fungus Penicillium sp. KFD28. $J$. Nat. Prod. 2019, 82, 2638-2644. [CrossRef] [PubMed]

26. Yang, B.; Tao, H.; Lin, X.; Wang, J.; Liao, S.; Dong, J.; Zhou, X.; Liu, Y. Prenylated indole alkaloids and chromone derivatives from the fungus Penicillium sp. SCSIO041218. Tetrahedron 2018, 74, 77-82. [CrossRef]

27. Zhou, G.; Sun, C.; Hou, X.; Che, Q.; Zhang, G.; Gu, Q.; Liu, C.; Zhu, T.; Li, D. Ascandinines A-D, indole diterpenoids from the sponge-derived fungus Aspergillus candidus HDN15-152. J. Org. Chem. 2021, 86, 2431-2436. [CrossRef]

28. Ivanets, E.V.; Yurchenko, A.N.; Smetanina, O.F.; Rasin, A.B.; Zhuravleva, O.I.; Pivkin, M.V.; Popov, R.S.; Von Amsberg, G.; Afiyatullov, S.H.; Dyshlovoy, S.A. Asperindoles A-D and a p-terphenyl derivative from the ascidian-derived fungus Aspergillus sp. KMM 4676. Mar. Drugs 2018, 16, 232. [CrossRef]

29. Cai, R.; Jiang, H.; Xiao, Z.; Cao, W.; Yan, T.; Liu, Z.; Lin, S.E.; Long, Y.; She, Z. (-)-and (+)-Asperginulin A, a pair of indole diketopiperazine alkaloid dimers with a $6 / 5 / 4 / 5 / 6$ pentacyclic skeleton from the mangrove endophytic fungus Aspergillus sp SK-28. Org. Lett. 2019, 21, 9633-9636. [CrossRef]

30. Li, P.; Zhang, M.; Li, H.; Wang, R.; Hou, H.; Li, X.; Liu, K.; Chen, H. New prenylated indole homodimeric and pteridine alkaloids from the marine-Derived fungus Aspergillus austroafricanus Y32-2. Mar. Drugs 2021, 19, 98. [CrossRef]

31. Shaker, S.; Fan, R.Z.; Li, H.J.; Lan, W.J. A pair of novel bisindole alkaloid enantiomers from marine fungus Fusarium sp. XBB-9. Nat. Prod. Res. 2021, 35, 1497-1503. [CrossRef] [PubMed]

32. Yuan, M.X.; Qiu, Y.; Ran, Y.Q.; Feng, G.K.; Deng, R.; Zhu, X.F.; Lan, W.J.; Li, H.J. Exploration of indole alkaloids from marine fungus Pseudallescheria boydii F44-1 using an amino acid-directed strategy. Mar. Drugs 2019, 17, 77. [CrossRef]

33. Buttachon, S.; Ramos, A.A.; Inácio, Â.; Dethoup, T.; Gales, L.; Lee, M.; Costa, P.M.; Silva, A.M.S.; Sekeroglu, N.; Rocha, E.; et al Bis-indolyl benzenoids, hydroxypyrrolidine derivatives and other constituents from cultures of the marine sponge-associated fungus Aspergillus candidus KUFA0062. Mar. Drugs 2018, 16, 119. [CrossRef]

34. Huang, S.; Chen, H.; Li, W.; Zhu, X.; Ding, W.; Li, C. Bioactive chaetoglobosins from the mangrove endophytic fungus Penicillium chrysogenum. Mar. Drugs 2016, 14, 172. [CrossRef]

35. Zhu, X.; Zhou, D.; Liang, F.; Wu, Z.; She, Z.; Li, C. Penochalasin K, a new unusual chaetoglobosin from the mangrove endophytic fungus Penicillium chrysogenum V11 and its effective semi-synthesis. Fitoterapia 2017, 123, 23-28. [CrossRef]

36. Qi, J.; Jiang, L.; Zhao, P.; Chen, H.; Jia, X.; Zhao, L.; Dai, H.; Hu, J.; Liu, C.; Shim, S.H.; et al. Chaetoglobosins and azaphilones from Chaetomium globosum associated with Apostichopus japonicus. Appl. Microbiol. Biot. 2020, 104, 1545-1553. [CrossRef]

37. Luo, X.W.; Gao, C.H.; Lu, H.M.; Wang, J.M.; Su, Z.Q.; Tao, H.M.; Zhou, X.F.; Yang, B.; Liu, Y.H. HPLC-DAD-guided isolation of diversified chaetoglobosins from the coral-associated fungus Chaetomium globosum C2F17. Molecules 2020, 25, 1237. [CrossRef] [PubMed]

38. Zhang, Z.; Min, X.; Huang, J.; Zhong, Y.; Wu, Y.; Li, X.; Deng, Y.; Jiang, Z.; Shao, Z.; Zhang, L.; et al. Cytoglobosins H and I, new antiproliferative cytochalasans from deep-sea-derived fungus Chaetomium globosum. Mar. Drugs 2016, 14, 233. [CrossRef]

39. Li, J.; Hu, Y.; Hao, X.; Tan, J.; Li, F.; Qiao, X.; Chen, S.; Xiao, C.; Chen, M.; Peng, Z.; et al. Raistrickindole A, an anti-HCV oxazinoindole alkaloid from Penicillium raistrickii IMB17-034. J. Nat. Prod. 2019, 82, 1391-1395. [CrossRef] [PubMed] 
40. Kong, F.D.; Zhang, S.L.; Zhou, S.Q.; Ma, Q.Y.; Xie, Q.Y.; Chen, J.P.; Li, J.H.; Zhou, L.M.; Yuan, J.Z.; Hu, Z.; et al. Quinazolinecontaining indole alkaloids from the marine-derived fungus Aspergillus sp. HNMF114. J. Nat. Prod. 2019, 82, 3456-3463. [CrossRef]

41. Limbadri, S.; Luo, X.; Lin, X.; Liao, S.; Wang, J.; Zhou, X.; Yang, B.; Liu, Y. Bioactive novel indole alkaloids and steroids from deep sea-derived fungus Aspergillus fumigatus SCSIO 41012. Molecules 2018, 23, 2379. [CrossRef] [PubMed]

42. Liu, S.S.; Yang, L.; Kong, F.D.; Zhao, J.H.; Yao, L.; Yuchi, Z.G.; Ma, Q.Y.; Xie, Q.Y.; Zhou, L.M.; Guo, M.F.; et al. Three new quinazoline-containing indole alkaloids from the marine-derived fungus Aspergillus sp. HNMF114. Front. Microbiol. 2021, 12, 1111. [CrossRef]

43. Cho, K.H.; Sohn, J.H.; Oh, H. Isolation and structure determination of a new diketopiperazine dimer from marine-derived fungus Aspergillus sp. SF-5280. Nat. Prod. Res. 2018, 32, 214-221. [CrossRef] [PubMed]

44. Xie, C.L.; Xia, J.M.; Su, R.Q.; Li, J.; Liu, Y.; Yang, X.W.; Yang, Q. Bacilsubteramide A, a new indole alkaloid, from the deep-seaderived Bacillus subterraneus 11593. Nat. Prod. Res. 2018, 32, 2553-2557. [CrossRef]

45. Anjum, K.; Kaleem, S.; Yi, W.; Zheng, G.; Lian, X.; Zhang, Z. Novel antimicrobial indolepyrazines A and B from the marineassociated Acinetobacter sp. ZZ1275. Mar. Drugs 2019, 17, 89. [CrossRef]

46. Song, Y.; Yang, J.; Yu, J.; Li, J.; Yuan, J.; Wong, N.K.; Ju, J. Chlorinated bis-indole alkaloids from deep-sea derived Streptomyces sp SCSIO 11791 with antibacterial and cytotoxic activities. J. Antibiot. 2020, 73, 542-547. [CrossRef]

47. Okada, M.; Sugita, T.; Wong, C.P.; Wakimoto, T.; Abe, I. Identification of pyridinium with three indole moieties as an antimicrobial agent. J. Nat. Prod. 2017, 80, 1205-1209. [CrossRef]

48. Kwon, O.S.; Ahn, S.; Jeon, J.; Park, I.G.; Won, T.H.; Sim, C.J.; Park, H.; Oh, D.C.; Oh, K.B.; Noh, M.; et al. Psammocindoles A-C: Isolation, synthesis, and bioactivity of indole- $\gamma$-lactams from the sponge Psammocinia vermis. Org. Lett. 2021, 23, $4667-4671$. [CrossRef] [PubMed]

49. Guzii, A.G.; Makarieva, T.N.; Denisenko, V.A.; Gerasimenko, A.V.; Udovenko, A.A.; Popov, R.S.; Dmitrenok, P.S.; Golotin, V.A.; Fedorov, S.N.; Grebnev, B.B.; et al. Guitarrins A-E and aluminumguitarrin A: 5-azaindoles from the Northwestern Pacific marine sponge Guitarra fimbriata. J. Nat. Prod. 2019, 82, 1704-1709. [CrossRef]

50. Wang, Q.; Tang, X.L.; Luo, X.C.; de Voog, N.J.; Li, P.L.; Li, G.Q. Aplysinopsin-type and bromotyrosine-derived alkaloids from the south China sea sponge Fascaplysinopsis reticulata. Sci. Rep. 2019, 9, 1-10. [CrossRef]

51. Di, X.; Rouger, C.; Hardardottir, I.; Freysdottir, J.; Molinski, T.F.; Tasdemir, D.; Omarsdottir, S. 6-bromoindole derivatives from the Icelandic marine sponge Geodia barretti: Isolation and anti-Inflammatory activity. Mar. Drugs 2018, 16, 437. [CrossRef] [PubMed]

52. Wright, A.E.; Killday, K.B.; Chakrabarti, D.; Guzmán, E.A.; Harmody, D.; McCarthy, P.J.; Pitts, T.; Pomponi, S.A.; Reed, J.K.; Roberts, B.F.; et al. Dragmacidin G, a bioactive bis-indole alkaloid from a deep-water sponge of the genus Spongosorites. Mar. Drugs 2017, 15, 16. [CrossRef] [PubMed]

53. Hitora, Y.; Takada, K.; Ise, Y.; Okada, S.; Matsunaga, S. Dragmacidins G and H, bisindole alkaloids tethered by a guanidino ethylthiopyrazine moiety, from a Lipastrotethya sp. marine sponge. J. Nat. Prod. 2016, 79, 2973-2976. [CrossRef]

54. Liu, H.B.; Lauro, G.; O'Connor, R.D.; Lohith, K.; Kelly, M.; Colin, P.; Bifulco, G.; Bewley, C.A. Tulongicin, an antibacterial tri-indole alkaloid from a deep-water Topsentia sp. sponge. J. Nat. Prod. 2017, 80, 2556-2560. [CrossRef] [PubMed]

55. Wang, D.; Feng, Y.; Murtaza, M.; Wood, S.; Mellick, G.; Hooper, J.N.; Quinn, R.J. A grand challenge: Unbiased phenotypic function of metabolites from Jaspis splendens against Parkinson's disease. J. Nat. Prod. 2016, 79, 353-361. [CrossRef]

56. Ragini, K.; Piggott, A.M.; Karuso, P. Bisindole alkaloids from a New Zealand deep-sea marine sponge Lamellomorpha strongylata. Mar. Drugs 2019, 17, 683. [CrossRef]

57. Jennings, L.K.; Khan, N.; Kaur, N.; Rodrigues, D.; Morrow, C.; Boyd, A.; Thomas, O.P. Brominated bisindole alkaloids from the Celtic Sea sponge Spongosorites calcicola. Molecules 2019, 24, 3890. [CrossRef]

58. Cruz, P.G.; Leal, J.F.M.; Daranas, A.H.; Pérez, M.; Cuevas, C. On the mechanism of action of dragmacidins I and J, two new representatives of a new class of protein phosphatase 1 and 2A inhibitors. ACS Omega 2018, 3, 3760-3767. [CrossRef]

59. Park, J.S.; Cho, E.; Hwang, J.Y.; Park, S.C.; Chung, B.; Kwon, O.S.; Sim, C.J.; Oh, D.C.; Oh, K.B.; Shin, J. Bioactive bis (indole) alkaloids from a Spongosorites sp. sponge. Mar. Drugs 2021, 19, 3. [CrossRef] [PubMed]

60. El-Hawary, S.S.; Sayed, A.M.; Mohammed, R.; Hassan, H.M.; Rateb, M.E.; Amin, E.; Mohammed, T.A.; El-Mesery, M.; Muhsinah, A.B.; Alsayari, A.; et al. Bioactive brominated oxindole alkaloids from the Red Sea sponge Callyspongia siphonella. Mar. Drugs 2019, 17, 465. [CrossRef]

61. Moosmann, P.; Taniguchi, T.; Furihata, K.; Utsumi, H.; Ise, Y.; Morii, Y.; Yamawaki, N.; Takatani, T.; Arakawa, O.; Okada, S.; et al Myrindole A, an antimicrobial bis-indole from a marine sponge Myrmekioderma sp. Org. Lett. 2021, 23, 3477-3480. [CrossRef] [PubMed]

62. Kleks, G.; Holland, D.C.; Kennedy, E.K.; Avery, V.M.; Carroll, A.R. Antiplasmodial alkaloids from the Australian bryozoan Amathia lamourouxi. J. Nat. Prod. 2020, 83, 3435-3444. [CrossRef]

63. Di, X.; Wang, S.; Oskarsson, J.T.; Rouger, C.; Tasdemir, D.; Hardardottir, I.; Freysdottir, J.; Wang, X.; Molinski, T.F.; Omarsdottir, S. Bromotryptamine and imidazole alkaloids with anti-inflammatory activity from the bryozoan Flustra foliacea. J. Nat. Prod. 2020, 83, 2854-2866. [CrossRef]

64. Hansen, K.Ø.; Isaksson, J.; Bayer, A.; Johansen, J.A.; Andersen, J.H.; Hansen, E. Securamine derivatives from the Arctic bryozoan Securiflustra securifrons. J. Nat. Prod. 2017, 80, 3276-3283. [CrossRef] 
65. Li, M.C.; Sun, W.S.; Cheng, W.; Liu, D.; Liang, H.; Zhang, Q.Y.; Lin, W.H. Four new minor brominated indole related alkaloids with antibacterial activities from Laurencia similis. Bioorg. Med. Chem. Lett. 2016, 26, 3590-3593. [CrossRef] [PubMed]

66. Cai, Y.S.; Sun, J.Z.; Tang, Q.Q.; Fan, F.; Guo, Y.W. Acanthiline A, a pyrido[1,2-a] indole alkaloid from Chinese mangrove Acanthus ilicifolius. J. Asian Nat. Prod. Res. 2018, 20, 1088-1092. [CrossRef] [PubMed]

67. Kobayashi, M.; Aoki, S.; Gato, K.; Matsunami, K.; Kurosu, M.; Kitagawa, I. Marine natural products. XXXIV. Trisindoline, a new antibiotic indole trimer, produced by a bacterium of Vibrio sp. separated from the marine sponge Hyrtios altum. Chem. Pharm. Bull. 1994, 42, 2449-2451. [CrossRef] [PubMed] 